\title{
Recycling of wood-reinforced poly-(propylene) composites: A numerical and experimental approach
}

\author{
Guillaume Barteau $^{\mathrm{a}}$, Wiyao Azoti ${ }^{\mathrm{b}, \mathrm{f}}$, Maxime Gautreau ${ }^{\mathrm{c}}$, Charles Francart ${ }^{\mathrm{b}}$, Guillaume Alès ${ }^{\mathrm{d}}$, \\ Hamdi Jmal $^{\mathrm{b}}$, Jérôme Bouchet ${ }^{\mathrm{e}}$, Antoine Kervoëlen ${ }^{\mathrm{a}}$, Johnny Beaugrand ${ }^{\mathrm{c}}$, Nadia Bahlouli ${ }^{\mathrm{b}}$, \\ Alain Bourmaud ${ }^{\text {a, } *}$ \\ ${ }^{\text {a } U n i v . ~ B r e t a g n e ~ S u d, ~ U M R ~ C N R S ~ 6027, ~ I R D L, ~ L o r i e n t, ~ F r a n c e ~}$ \\ ${ }^{\mathrm{b}}$ ICube Laboratory, University of Strasbourg-CNRS, 2 rue Boussingault, 67000, Strasbourg, France \\ ${ }^{\mathrm{c}}$ INRAE, UR1268 BIA Biopolymères Interactions Assemblages, F-44316, Nantes, France \\ ${ }^{\mathrm{d}}$ Addiplast SA, ZI de Campine, 43620 Saint-Pal-de-Mons, France \\ e COPFIMO, 37 Boulevard de la Nation, 43120 Monistrol-sur-Loire, France \\ ${ }^{\mathrm{f}}$ ECAM Strasbourg-Europe, 2 rue de Madrid, 67300 Schiltigheim, France
}

\section{A R T I C L E I N F O}

\section{Keywords:}

Wood

Flax

Mechanical properties

Injection moulding

Numerical modelling

\begin{abstract}
A B S T R A C T
Injection moulded composite materials reinforced with wood fibres or particles can offer a credible alternative to other plant-derived fibres, particularly from an economic and environmental point of view. In this study, we compared the recycling behaviour of poly-(propylene) composites reinforced with ground wood particles versus wood and flax fibre reinforced composites. An experimental and numerical approach was used. In spite of the mechanical and morphological performances of fibres which were initially poorer than those of long fibres, the wood particles demonstrated their reinforcement potential $(+84 \%$ and $+14 \%$, for the Young's modulus and the strength at max, respectively, compared to the pure matrix), due to their good adhesion with the matrix and also to the stability of their aspect ratio after recycling (-24\% after 5 injection cycles against $-66 \%$ and $-61 \%$ for long flax and wood fibres, respectively). The numerical model developed and fed by the mechanical and morphological measurements carried out on the reinforcements made it possible to compare the experimental and numerical values. Overall, a close match was obtained between the two sets of parameters. The small differences obtained can be explained by the increase in fibre dispersion as the recycling process progresses, as well as by the possible increase in wood stiffness after several processing cycles.
\end{abstract}

\section{Introduction}

To respect the Paris Climate Agreement (United Nations Framework Convention on Climate Change, 2015) and new European environmental regulations about $\mathrm{CO} 2$ emissions (The European parliament and the council of the European union, 2009) and recycling (The European parliament and the council of the European union, 2000), automotive industries are moving towards natural products to avoid the use of petroleum products (E-glass fibres for example), which strongly contribute to global warming. Integration of plant fibres as a composite polymer reinforcement is a suitable alternative. Wood could be an interesting product to reinforce composites, especially since it can be found locally and because co-products are available (Rafighi et al., 2014). However, wood fibres have mechanical properties which are of less interest than other plant fibres like flax for example (Bourmaud et al., 2018). Different intrinsic factors such as a low fibre aspect ratio or cellulose content as well as a high microfibrillar angle value (MFA) may be the cause of its moderate mechanical properties (Bourmaud and Baley, 2009). Another reason for the relative low apparent mechanical properties is the considerable size of the lumens in the wood fibres which penalize both the apparent strength and Young's modulus (Tanguy et al., 2016).

There is a great deal of literature concerning the recycling of plant fibres reinforced composites and the morphological damage occurring during extrusion or injection moulding steps (Albrecht et al., 2018; Beaugrand and Berzin, 2013; Berzin et al., 2014) ; in the case of flax, breakage preferentially occurs in the kink-band defects, which can be considered as an area of weakness, especially due to MFA

\footnotetext{
* Corresponding author.

E-mail address: alain.bourmaud@univ-ubs.fr (A. Bourmaud).
} 
rearrangements and a low cellulose crystallization rate. These kinds of defects do not exist in wood, which generally maintains a relative conservation of its initial length, even after several processing cycles (Dickson et al., 2014a). Due to the specific architecture of the plant and efficient mechanical extraction, flax reinforcements are able to divide during composite processing which enables a quasi-stable value of the fibre aspect ratio to be maintained with the processing cycles (Oksman et al., 2009). This assessment is in favour of stable composite mechanical performances. Nevertheless the high morphological sensitivity of fibres to processing can be a major drawback due to the significant increase of fine particle elements $(<200 \mu \mathrm{m})$ which can strongly penalizes the mechanical performances of associated composites (Bourmaud et al., 2019).

In order to help the designer who wishes to identify the best morphologies or natures of fibres and matrices, the development of a predictive model is a relevant tool. Several works have been performed in such a domain for bio-composites. Using analytical micro-mechanic formulations and experimental micrographs, Zuccarello et al. (Zuccarello and Scaffaro, 2017) determined the mechanical properties of natural short and long fibres reinforced PLA or epoxy matrix composites. They also demonstrated the impact of the fibre type (short or long) and treatment on the mechanical strength of the composite. Analytical models and rule of mixtures (ROM) as well as the Halpin-Tsai approach have been used in conjunction with a design of experiments (DOE) by Silva et al. (Da Silva et al., 2012) to study the influence of the type of fibres, the volume fraction and the modified matrix phase on the mechanical responses of hybrid natural fibres reinforced composites.

Scida et al. (Scida et al., 2017) determined the elastic properties of the flax/epoxy woven fibre composite taking into account the anisotropy due to the fibre morphology and using Ashby-type plots, Sobczak et al. (Sobczak et al., 2012) compared the mechanical performance of injection moulded natural fibre composites and wood polymer composites to conventional fibres reinforced polypropylene composites. They described the contribution of the mechanical filler properties since the composite behaviours are a result of its constituent properties and their interactions.

Most studies focus on the calculation of elastic properties as described previously. Few models are available to describe the nonlinear stress-strain curve by integrating morphological elements of bio-based composites. The non-linear response of the composite is usually driven by the behaviour of the matrix. The latter undergoes rate-(in) dependent behaviour which may lead to a damage initiation. Using the so-called multisite modelling, Azoti et al. (Azoti et al., 2015) derived effective properties, obtained by micromechanics for a rate-independent elasto-plasticity matrix. Moreover, accounting for the damage evolution and an interfacial discontinuity is studied (Azoti and Elmarakbi, 2017; Tchalla et al., 2015) for polymer matrix composites. Recently, Azoti et al. (Azoti et al., 2019) derived the effective properties of a rate dependent elasto(visco)-plastic matrix reinforced by thermoelastic fibres applied to flax/polypropylene PP composites.

The aim of this work is to finely study the mechanical and recycling behaviour of PP-wood fibres composites in comparison with reference reinforcement. Flax fibres and long and individualized wood fibres will be also studied. Firstly, an accurate study of the fibres morphology will be explored using scanning electronic microscopy (SEM) and a morphological dynamic analyser. Then, the mechanical behaviour of the composites will be explored by static and dynamic tensile tests and a modelling study will be implemented to develop prediction tools for plant fibre composite mechanical behaviour. This numerical and experimental approach was carried out on the initial composites but also after a recycling phase in order to evaluate the mechanical performances and the predictive capacity of the model at the different stages of the life cycle of the products.

\section{Materials and methods}

\subsection{Materials}

The matrix used for injection moulded composites manufacturing is a poly-(propylene) (PP) block copolymer from Exxon ${ }^{\circledR}$. The melt flow index of this PP injection grade is $\sim 100 \mathrm{~g} / 10 \mathrm{~min}$ at $230{ }^{\circ} \mathrm{C}$ (under a load of $2.16 \mathrm{~kg}$ ). In order to improve the compatibility between the fibres and the PP matrix, we used a maleic anhydride grafted PP (PPgMA).

The flax fibre (linum usitassinum L., Alizé variety) used in this study come from plants which were sawed in March 2015 and harvested at the end of June 2015 in Normandy (France). Then, plants were dew-retted during 6 weeks, scutched and hackled. To prepare the compounding stage, flax fibres were then mechanically cut at a $2 \mathrm{~mm}$ length.

The wood used for the wood fibres came from logs of hardwood from France. Fibres were calibrated with different grinding steps to obtain an average length of $1 \mathrm{~mm}$. In the following study, these fibres are named Vegetal Technic (VT).

WoodForce Fast pellets (WF) are made of short fibres of softwood and are produced by Sonae Arauco (Maia, Portugal). The origin of the wood is unknown.

\subsection{Compounding and processing}

Plant fibres were used as is (without pre-drying) but with specifications for their humidity content. A twin-screw extruder (Coperion ZSK 26MC) was used for the compounding stage, at $250 \mathrm{rpm}$ and $190^{\circ} \mathrm{C}$. Then, the extruded filament was water cooled and cut in pellets from 2 to $4 \mathrm{~mm}$ long.

An injection moulding machine (Battenfeld, 80 tons) was used to produce ISO-527 normalized specimens. The screw temperature and the mould temperature were $190^{\circ} \mathrm{C}$ and $30^{\circ} \mathrm{C}$, respectively, for all the compounds. After the first injection cycle, 20 parts were kept for mechanical testing, the remaining material was ground again and injected. The grinding process was performed using a CMB 2700 rotary blade grinder to obtain pellets, at $500 \mathrm{rpm}$ at room temperature with a $3.5 \mathrm{~mm}$ sieve. Six successive recycling stages were performed for each batch. In the manuscript, these cycles are named recycling cycle $0,1,2,3,4$ and 5 . Cycle 0 corresponds to the first injection, without any recycling.

Table 1 shows the detail of the different formulations elaborated and investigated in the present work.

\subsection{Quasi static tensile tests}

Samples were tensile tested at room temperature of $23^{\circ} \mathrm{C}$, with a humidity of $48 \%$ according to ISO 527 using an MTS Criterion Model C42.503E tensile machine equipped with a $5 \mathrm{kN}$ load cell (MTS, Eden Prairie, MN, USA) with a tensile speed of $1 \mathrm{~mm} / \mathrm{min}$. To monitor the displacement, an axial MTS extensometer HTE was used (nominal length $25.0 \mathrm{~mm}$ ). Five reproducible tests were selected to calculate average mechanical values.

Table 1

Composition of the four studied compounds and the reference PP. For all the samples, the fibre weight fraction is $30 \%$.

\begin{tabular}{llllll}
\hline Sample & $\begin{array}{l}\text { PP } \\
(\%-v o l)\end{array}$ & $\begin{array}{l}\text { PP-g-MA } \\
(\%-v o l)\end{array}$ & $\begin{array}{l}\text { Vegetal } \\
\text { Technic (VT) } \\
(\%-v o l)\end{array}$ & $\begin{array}{l}\text { Flax (FF) } \\
\text { (\%-vol) }\end{array}$ & $\begin{array}{l}\text { WoodForce } \\
\text { (WF) (\%-vol) }\end{array}$ \\
\hline PP & 97 & 3 & - & - & - \\
PP-VT & 76.6 & 2.4 & 21.0 & - & - \\
PP-Flax & 77.2 & 2.4 & - & 20.4 & - \\
PP-WF & 76.6 & 2.4 & - & - & 21.0 \\
PP-VT/ & 76.9 & 2.4 & 10.5 & 10.2 & - \\
$\quad$ Flax & & & & & \\
\hline
\end{tabular}




\subsection{Charpy impact}

Samples were notched Charpy impact tested at room temperature using a Tinius Olsen machine. Tensile specimens were cut according to the ISO 179 standard with a sample size of $80 \times 10 \times 4 \mathrm{~mm}^{3}$.

Results were arithmetically averaged from at least 10 tests.

\subsection{Nanoindentation investigations}

The virgin fibres were embedded in an epoxy resin and then the samples were meticulously polished to a $1-\mu \mathrm{m}$ particle size finishing solution. Nanoindentation tests were performed with a Nanoindenter XP (MTS Nano Instruments) in controlled environment $\left(23 \pm 1{ }^{\circ} \mathrm{C}\right.$ and $50 \%$ $\mathrm{RH})$. A Berkovich diamond indenter was used and before the experiments, the area function was carefully calibrated thanks to a silica sample. Indentation tests were conducted with a constant penetration depth of the indenter of $120 \mathrm{~nm}$.

The nanoindentation hardness is defined as the indentation load divided by the projected contact area and the effective elastic modulus Er can be calculated with the relationships as illustrated in Eq (1):

$S=2 a E_{r}=\frac{2 \beta}{\sqrt{\pi}} E_{r} \sqrt{A}$

where $\mathrm{a}$ is the contact radius and $\beta$ is a constant depending on the geometry of the indenter (1.034 for a Berkovitch tip). The reduced modulus, Er, accounting for deformation of both the indenter and the sample is given by:

$\frac{1}{E_{r}}=\frac{\left(1-\nu^{2}\right)}{E}+\frac{\left(1-\nu_{i}^{2}\right)}{E_{i}}$

In the above equation, Ei (1140 GPa) and $v i$ (0.07) are the elastic properties of the diamond indenter. $\mathrm{E}$ and $v$ are the elastic modulus and Poisson's ratio of the sample.

Indents were made in the $\mathrm{S} 2$ layer of the flax fibres; 50 indents were performed for each batch but between 1 and 5 indents were performed in each fibre. Consequently, the number of fibres studied per batch is around 20. The nanoindentation modulus and hardness calculated are average values from 80 to $120 \mathrm{~nm}$.

\subsection{Particle size analysis}

The morphometry analysis was done thanks to a dynamic image analyser called QICPIC (SympaTec GmbH, Germany). The image analysis was done thanks to the PAQXOS software (SympaTec GmbH, Germany), with two main indicators as the LEFI (Length of the Fiber) and the DIFI (Diameter of the Fiber) for the particle length and diameter respectively. Several morphological parameters of interested were selected as the (a) the particle length, which is defined as the shortest direct path, along the skeleton of the fibre between their farthest endpoints (without loops or deviations), (b) the particle diameter which is the quotient of the total projection area and the sum of all lengths of the branches of the main skeleton, (c) the particle aspect ratio, which is defined as the length over the diameter.

In addition, other samples from morphometric characterisation were further conducted on particles from the PP matrix composites. For that, the PP was dissolved with o-xylene (Sigma Aldrich, France) at $150{ }^{\circ} \mathrm{C}$ during 3 days with the reflux method. Particles obtained were washed with boiling xylene and further matrix traces removed with acetone. All the samples were dried before analysis $\left(60^{\circ} \mathrm{C}\right.$ overnight).

Samples were characterised with the he dynamic particle analyser with a liquid or a dry dispersion unit depending on the nature of samples. The non-processed flax and wood fibers, which were particles are easy to separate, were tested with the dry system (VIBRI, SympaTec $\mathrm{GmbH}$, Germany) all the others samples showing aggregation after PP extraction, were tested with a liquid dispersion unit (MIXCEL, SympaTec
$\mathrm{GmbH}$, Germany). In that case, the samples were pre-dispersed in $5 \mathrm{~mL}$ of ethanol before being diluted appropriately in water. Between 20,000 and 10 millions of particles was analysed according to the samples studied. Every sample was analysed in duplicate.

\subsection{Monosaccharide composition}

The content of monosaccharide was quantified by operating a homogenization step by cryogrinding (SPEX 6700 freezer Mill) of approximately $1 \mathrm{~g}$ of samples. The powdered samples were then hydrolysed ( $5 \mathrm{mg}$ per assay) in $12 \mathrm{M} \mathrm{H}_{2} \mathrm{SO}_{4}$ (Sigma Aldrich) for $2 \mathrm{~h}$ at $25{ }^{\circ} \mathrm{C}$ followed by additional hydrolysis of $2 \mathrm{~h}$ at $100{ }^{\circ} \mathrm{C}$ in diluted $1.5 \mathrm{M}$ $\mathrm{H}_{2} \mathrm{SO}_{4}$ in presence of inositol as internal standard. Neutral monosaccharides (arabinose, rhamnose, fucose, glucose, xylose, galactose and mannose) were analysed as their alditol acetate derivatives (Blakeney et al., 1983) by gas-liquid chromatography (Perkin Elmer, Clarus 580, Shelton, CT, USA) equipped with an DB 225 capillary column (J\&W Scientific, Folsorn, CA, USA) at $205{ }^{\circ} \mathrm{C}$, with $\mathrm{H}_{2}$ as the carrier gas. For calibration pupose; we used standards of carbohydrate solutions of three known concentrations. Analyses were performed in three independent assays. The total monosaccharide content is the sum of each monosaccharide amount, and is expressed as the percentage of the dry matter mass.

\subsection{Lignin content}

The Lignin content was quantified in homogenised powdered particles of samples. Lignin was assess by spectrophotometry following the acetyl bromide method (Hatfield and Fukushima, 2005) on mass weight samples of approx. $20 \mathrm{mg}$ per essay, The chemicals were laboratory grade from Sigma Aldrich and the analyses were performed in at four independent assays, with lignin expressed as the percentage of the dry matter mass.

\subsection{SEM analysis}

Polished sections of tensile specimens were analysed using scanning electron microscopy (SEM). The samples were sputter-coated with a thin layer of gold in an Edwards Sputter Coater and analysed with a Jeol JSM $6460 \mathrm{~L} V$ electron scanning microscope.

\subsection{Mechanical modelling}

\subsubsection{Effective properties of the composite}

Let us consider a representative volume element RVE, which is composed of inclusions embedded within a matrix phase. From a micromechanics point of view, the effective properties of this composite material are given by:

$\boldsymbol{C}^{e f f}=\boldsymbol{c}^{0}+\sum_{I=1}^{N} f_{I}\left(\boldsymbol{c}^{I}-\boldsymbol{c}^{0}\right): \boldsymbol{A}^{I}$

where $c^{0}$ stands for the elastic stiffness tensor of the matrix whereas $c^{I}$, $\boldsymbol{A}^{I}, f_{I}$ represents the elastic stiffness tensor, the global strain concentration tensor and the volume fraction of the inclusion phase $I$, respectively. The global strain concentration tensor $\boldsymbol{A}^{I}$ contains all the information about the microstructure. Its expression is given by (Vieville et al., 2066):

$\left\{\begin{array}{l}\boldsymbol{A}^{I}=\boldsymbol{a}^{I}:\left\langle\boldsymbol{a}^{I}\right\rangle^{-1} \\ \boldsymbol{a}^{I}=\left[\mathrm{I}+\boldsymbol{T}^{I I}: \Delta \boldsymbol{c}^{I}\right]^{-1}\end{array}\right.$

with $\Delta \boldsymbol{c}^{I}=\boldsymbol{c}^{I}-\boldsymbol{C}^{r}$. The tensor $\boldsymbol{C}^{r}$ is defined as the uniform stiffness tensor of a homogeneous reference medium. The tensor $\boldsymbol{a}^{I}$ stands for the local strain concentration tensor and the tensor $\boldsymbol{T}^{I I}$ represents the interaction 
between inclusions. The expression of $\boldsymbol{T}^{I I}$ gives:

$\boldsymbol{T}^{I I}=\mathrm{S}:\left(\boldsymbol{c}^{0}\right)^{-1}$

where S represents the Eshelby's tensor (Eshelby and Peierls, 1957). The expression of $\boldsymbol{a}^{I}$ is given by:

$\boldsymbol{a}^{I}=\left[\mathrm{I}+\boldsymbol{T}^{I I}: \Delta \boldsymbol{c}^{I}\right]^{-1}=\left[\mathrm{I}+\mathrm{S}:\left(\boldsymbol{c}^{0}\right)^{-1}: \Delta \boldsymbol{c}^{I}\right]^{-1}$

It is worth highlighting that the Eshelby's tensor S depends on the aspect ratio $A R$ of the ellipsoidal inclusion and the material properties of the surrounding matrix $c^{0}$. Herein the aspect ratio of the inclusion is considered by the ratio of the length by the diameter of the inclusion. It gives:

$A R=\frac{L}{D}$

Finally, for the Mori-Tanaka scheme (Mori and Tanaka, 1973), the reference medium is assumed to be the matrix phase leading to $\boldsymbol{C}^{R}=\boldsymbol{c}^{0}$. Therefore, the average strain field inside the matrix is approximated by the strain within the reference medium, leading to $\boldsymbol{a}^{0}=\mathrm{I}$. The effective Mori-Tanaka properties $\boldsymbol{C}^{\text {eff }}$ are given as a function of the global strain concentration tensor of the matrix $\boldsymbol{A}^{0}$ given by (Vieville et al., 2006):

$$
\left\{\begin{array}{l}
\boldsymbol{A}^{0}=\boldsymbol{a}^{0}:\left\langle\boldsymbol{a}^{I}\right\rangle^{-1}=\left(f_{0} \mathrm{I}+\sum_{I=1}^{N} f_{I} \boldsymbol{a}^{I}\right)^{-1} \\
\boldsymbol{C}^{\text {eff }}=\sum_{I=0}^{N} f_{I} \boldsymbol{c}^{I} \boldsymbol{A}^{I}=\left(f_{0} \boldsymbol{c}^{0}+\sum_{I=1}^{N} f_{I} \boldsymbol{c}^{I} \boldsymbol{a}^{I}\right): \boldsymbol{A}^{0}
\end{array}\right.
$$

\subsubsection{Modelling of the nonlinear behaviour}

Let us consider a matrix undergoing a ductile damage behaviour. The effective stress $\widehat{\sigma}$ representing the undamaged matrix is related to the damaged stress $\sigma$ is given by:

$$
\left\{\begin{array}{l}
\boldsymbol{\sigma}=(1-D) \widehat{\boldsymbol{\sigma}} \\
0 \leq D<1
\end{array}\right.
$$

where $D$ represents the damage variable. The nonlinear behaviour can be derived from the classical $J_{2}$ plasticity and "Lemaitre-Chaboche" ductile damage model given by(Azoti and Elmarakbi, 2017; Tchalla et al., 2015):

$$
\left\{\begin{array}{l}
\boldsymbol{\sigma}=(1-D) \boldsymbol{C}^{e l}:\left(\boldsymbol{\varepsilon}-\boldsymbol{\varepsilon}^{p}\right) \\
f(\boldsymbol{\sigma}, R, D)=J_{2}\left(\widehat{\boldsymbol{\sigma}}-R(r)-\sigma_{Y}\right. \\
{ }^{p}=\dot{p} \widehat{\boldsymbol{N}}, \dot{p}=\left(\frac{2_{p}}{3}:{ }^{p}\right)^{1 / 2} \\
\dot{D}=\left(\frac{Y}{S_{0}}\right)^{s} \ddot{p} \text { if } p \geq p_{c} \text { and } D \leq D_{c}
\end{array}\right.
$$

In Eq. (10), $\boldsymbol{C}^{e l}$ represents the elastic stiffness tensor of the matrix and $R(p)$ represents the hardening function. The variable $p$ is the accumulated plastic strain. It drives the evolution of the damage within the matrix through the function $Y$ and the material parameters $S_{0}$ and $s$. Detailed information about the damage variables can be found in works by Doghri (Doghri, 2000). Based on the return mapping algorithm and the implicit integration scheme, two tangent moduli can be derived mainly by:

(11) The effective elasto-plastic $\widehat{\boldsymbol{C}}^{e p}$ tangent modulus, which is given by:

$$
\left\{\begin{array}{l}
\widehat{\boldsymbol{C}}^{e p}=\boldsymbol{C}^{e l}-\frac{(2 G)^{2}}{h} \widehat{\boldsymbol{N}} \otimes \widehat{\boldsymbol{N}} \\
\widehat{\boldsymbol{N}}=\frac{\partial f}{\partial \widehat{\boldsymbol{\sigma}}}=\frac{3}{2} \frac{\widehat{\boldsymbol{s}}}{\boldsymbol{J}_{2}(\widehat{\boldsymbol{\sigma}}} \\
h=3 G+\frac{d R}{d p}>0
\end{array}\right.
$$

(12) and the effective algorithmic $\widehat{\boldsymbol{C}}^{\text {alg }}$ tangent modulus :

$$
\left\{\begin{array}{l}
\widehat{\boldsymbol{C}}^{a \mathrm{lg}}=\widehat{\boldsymbol{C}}^{e p}-(2 G)^{2} \Delta p \frac{\widehat{\sigma}_{e q}}{\widehat{\sigma}_{e q}^{t r}} \frac{\partial \widehat{\boldsymbol{N}}}{\partial \widehat{\boldsymbol{\sigma}}} \\
\frac{\partial \widehat{\boldsymbol{N}}}{\partial \widehat{\boldsymbol{\sigma}}}=\frac{1}{\sigma_{e q}} \frac{3}{2} \mathrm{I}^{d e v}-\widehat{\boldsymbol{N}} \otimes \widehat{\boldsymbol{N}}
\end{array}\right.
$$

In Eqs. (11) and (12), $G$ denotes the material shear modulus while $N$ is the normal to the yield surface in the stress space. $\sigma_{e q}^{t r}$ represents a trial elastic predictor of $\sigma_{e q}$ and I ${ }^{d e v}$ stands for the deviatoric part of the fourth order identity tensor. A numerical algorithm developed in (Azoti and Elmarakbi, 2017) helps the computation of the nonlinear internal variables for instance $p$ and $D$. Therefore, Eq. (12) is fully determined, leading to the algorithmic tangent operator $C^{\text {alg. }}$ :

$\boldsymbol{C}^{a \lg }=(1-D) \widehat{\boldsymbol{C}}^{a \mathrm{lg}}$

The algorithmic tangent modulus $\boldsymbol{C}^{\text {alg }}$ will serve as the matrix constitutive behaviour in the Mori-Tanaka effective properties by Eq (8). It means:

$c^{0}=C^{a l g}$

\section{Results and discussion}

\subsection{Fibres properties before injection}

Fig. 1 presents SEM pictures of the three different fibres used in this study.

First of all, a clear difference in morphology can be observed between the VT (Fig. 1B) and WF (Fig. 1A) fibres. This is due to the fibre extraction and preparation process. WF fibres are obtained by grinding of wood, so pieces resulting from this grinding can be found, which can themselves be made up of an assembly of elementary wood cells. The process which makes it possible to produce WF fibres aims to individualize the elementary wood fibres, it makes it possible to obtain particles further divided and close to an elementary cell. This difference in morphology is confirmed by the results of a morphological analysis presented in Table 2.

It can be observed that a significant difference in cell individualisation exists between VT and WF fibres, the diameters of these fibres being $87.5 \pm 33.2 \mu \mathrm{m}$ and $30.8 \pm 14.6 \mu \mathrm{m}$, respectively. The diameters obtained by the WoodForce process makes it possible to have particle diameters close to that of the elementary fibres, which is between 10 and $60 \mu \mathrm{m}$ depending on the varieties of wood considered (Bourmaud et al., 2018); consequently their aspect ratio exhibits very relevant value (45.1). Flax fibres, on the other hand, have intermediate diameters with an average value of $64.3 \pm 33.9 \mu \mathrm{m}$; this dimension is larger than that of the elementary fibres, which is around $15 \mu \mathrm{m}$ (Baley and Bourmaud, 2014), irrespective of the variety of flax, and for normal growing conditions. These morphological characteristics are also corroborated by the details shown in Fig. 1D, E and F. The fibrous morphologies of flax fibres and WF fibres are clearly visible, and a clearly visible lumen can be seen on the WF fibres; note also the presence of kink-bands on the flax 

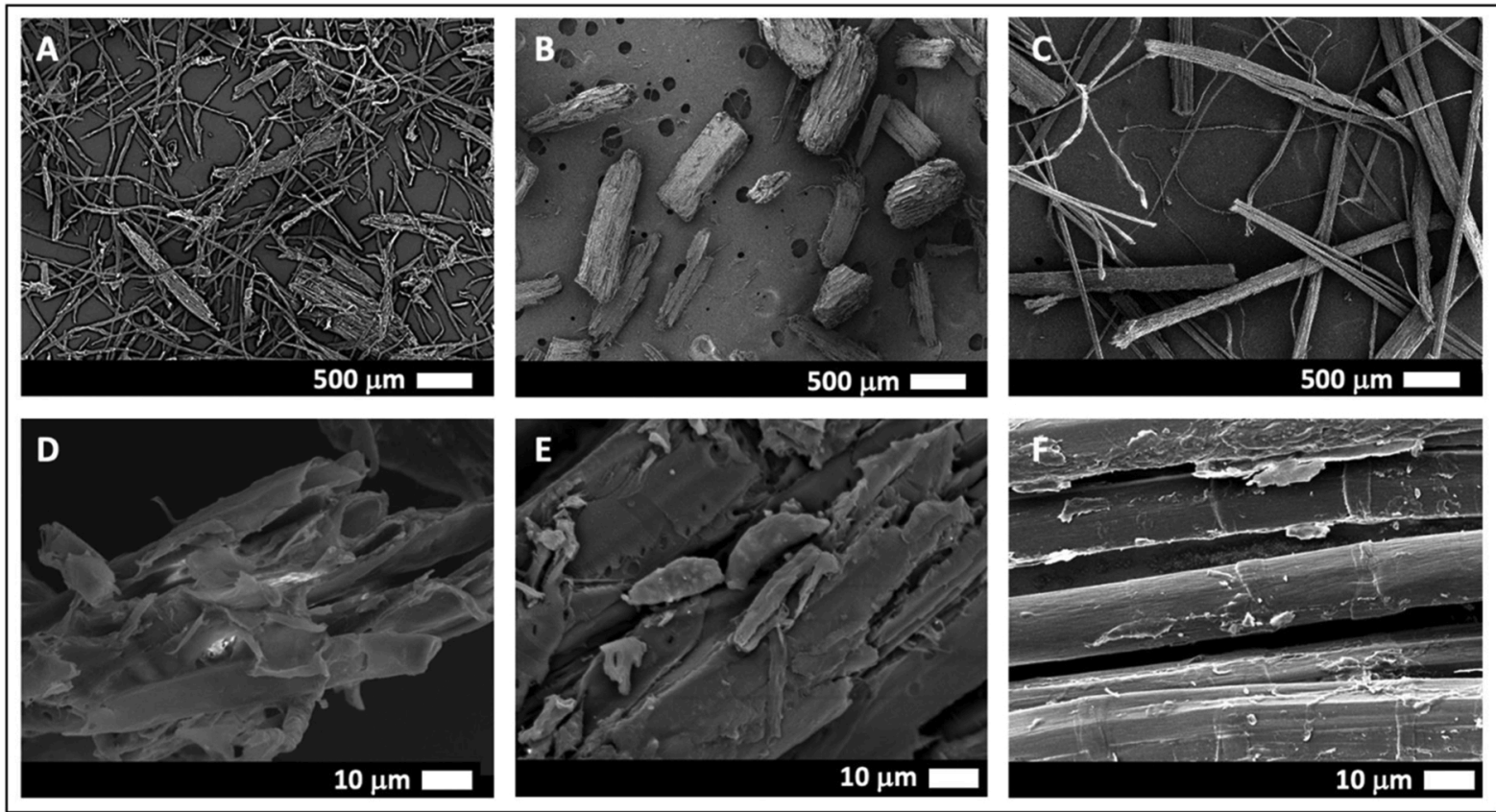

Fig. 1. Scanning electron microscopy (SEM) of WoodForce (A, D), Vegetal Technic (B, E) and Flax fibres (C, F).

Table 2

Equivalent fibres length LEFI, equivalent fibres diameter DIFI and aspect ratio of three not injected samples (Virgin WF, virgin VT, virgin Flax) and four samples after the first injection cycle (PP-Flax, PP-VT, PP-WF, PP-VT/Flax). The four last samples have been extracted before analysis (As detailed in paragraph 1.7).

\begin{tabular}{llll}
\hline Sample & $\begin{array}{l}\text { Fibres length LEFI } \\
(\mu \mathrm{m})\end{array}$ & $\begin{array}{l}\text { Fibres diameter DIFI } \\
(\mu \mathrm{m})\end{array}$ & $\begin{array}{l}\text { Aspect ratio L/ } \\
D\end{array}$ \\
\hline Virgin Flax & $2,060 \pm 626$ & $64.3 \pm 33.9$ & 32.1 \\
Virgin VT & $1,054 \pm 402$ & $87.5 \pm 33.2$ & 12.1 \\
Virgin WF & $1,386 \pm 893$ & $30.8 \pm 14.6$ & 45.1 \\
PP-Flax cycle 0 & $1,021 \pm 737$ & $27.2 \pm 14.6$ & 37.5 \\
PP-VT cycle 0 & $979 \pm 322$ & $107.4 \pm 38.0$ & 9.1 \\
PP-WF cycle 0 & $727 \pm 572$ & $42.0 \pm 42.1$ & 17.5 \\
PP-VT/Flax & $745 \pm 625$ & $40.4 \pm 32.6$ & 18.5 \\
$\quad$ cycle 0 & & & \\
\hline
\end{tabular}

fibres; these do not exist on the wood; they can constitute areas of fragility on flax fibres (Le Duc et al., 2011). Due to the grinding process, VT fibres are more like cell wall fractions than fibres, punctuations, which allow the sap to circulate, are visible and are a characteristic of wood. These three fibres also present significant differences in terms of length, the target cutting dimension for flax is $2 \mathrm{~mm}$. The value obtained by morphological analysis demonstrates the quality of cut used; for VT and WF fibres, the length is imposed not only by the preparation and sieving processes, but also by the short initial length of the fibres in the plant; those of flax can reach up to $80 \mathrm{~mm}$, those of wood are generally between 1 and $8 \mathrm{~mm}$ (Table 3). Logically these dimensions have an impact on the aspect ratios of the fibres, in this respect the most interesting fibre is the WF fibre which has an aspect ratio of 45.1 which is a particularly promising value for the reinforcement of composite materials (Kelly and Tyson, 1965).

Table 3 presents the mechanical properties of flax and wood fibres from literature. Flax fibres have a superior Young's modulus and

Table 3

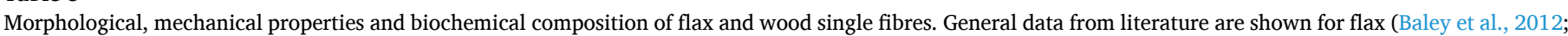

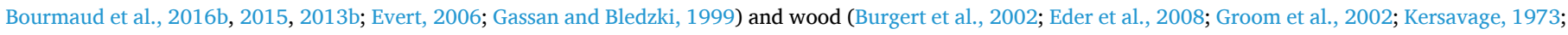

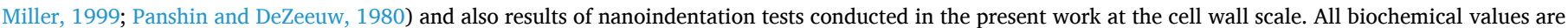

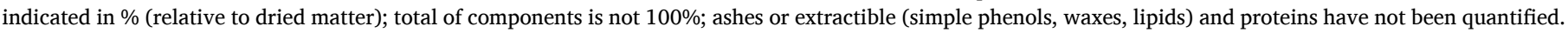

\begin{tabular}{|c|c|c|c|c|c|c|}
\hline Fibres & Length (mm) & Diameter $(\mathrm{mm})$ & Density $(\mathrm{g} / \mathrm{cm} 3)$ & Young Modulus (GPa) & Strength (MPa) & Strain at break (\%) \\
\hline Flax (Linum Usitatissimum L.) & $6-80$ & $12.4-23.9$ & $1.53-1.54$ & $37.2-75.1$ & $595-1,510$ & $1.6-3.6$ \\
\hline Wood (Different species) & $1-8$ & $10-60$ & $1.44-1.50$ & $15.4-27.5$ & $553-1,300$ & $3-7$ \\
\hline & \multicolumn{2}{|c|}{ Number of points } & \multicolumn{2}{|c|}{ Indentation modulus (GPa) } & \multicolumn{2}{|c|}{ Indentation hardness $(\mathrm{MPa})$} \\
\hline Flax & \multicolumn{2}{|l|}{32} & \multicolumn{2}{|c|}{$19.5 \pm 1.5$} & \multicolumn{2}{|c|}{$387 \pm 28$} \\
\hline WoodForce & \multicolumn{2}{|l|}{35} & \multicolumn{2}{|c|}{$14.8 \pm 1.6$} & \multicolumn{2}{|c|}{$362 \pm 37$} \\
\hline \multirow[t]{2}{*}{ Vegetal Technic } & \multicolumn{2}{|l|}{31} & \multicolumn{2}{|c|}{$14.5 \pm 1.3$} & \multicolumn{2}{|c|}{$323 \pm 32$} \\
\hline & & Flax & & WoodForce & & Vegetal technic \\
\hline Lignin content & & $1.95 \pm 0.48$ & & $27.50 \pm 0.72$ & & $28.80 \pm 0.95$ \\
\hline Arabinose & & $0.74 \pm 0.06$ & & $1.29 \pm 0.16$ & & $0.46 \pm 0.06$ \\
\hline Rhamnose & & $0.63 \pm 0.11$ & & $0.58 \pm 0.16$ & & $0.37 \pm 0.17$ \\
\hline Galactose & & $2.75 \pm 0.25$ & & $2.07 \pm 0.08$ & & $0.85 \pm 0.22$ \\
\hline Glucose & & $69.66 \pm 3.66$ & & $47.23 \pm 2.80$ & & $51.39 \pm 2.39$ \\
\hline Xylose & & $1.01 \pm 0.17$ & & $3.97 \pm 0.11$ & & $8.14 \pm 0.31$ \\
\hline Mannose & & $3.52 \pm 0.35$ & & $12.08 \pm 0.73$ & & $1.73 \pm 0.24$ \\
\hline Uronic acid & & $1.92 \pm 0.01$ & & $0.00 \pm 0.00$ & & $0.00 \pm 0.00$ \\
\hline
\end{tabular}


strength than wood fibres. These differences of properties mainly come from the biochemical composition of the two species, flax fibres having a higher crystalline cellulose fraction, but also come from the ultrastructure of the fibres themselves; in particular the microfibrillar angle (MFA) of flax fibres is considered to be around $8-10^{\circ}$, whereas it is generally between $20-30^{\circ}$ for conventional wood fibres (Bourmaud et al., 2018). These two parameters have a major impact on the longitudinal properties of flax fibres. Conversely, the transverse stiffness of flax is lower than that of wood, creating a very specific and strongly anisotropic mechanical behaviour which is confirmed by the nanoindentation tests (Table 3). Due to the very short length of wood fibres, except with specific and very time-consuming protocols (Burgert et al., 2005; Kersavage, 1973) it is not possible to directly tensile test wood cell walls.

To solve this issue, the mechanical properties of the 3 fibres were compared using nanoindentation experiments; as expected, flax exhibits a slightly higher indentation modulus compared to VT or WF fibres. Nevertheless, the difference is not as significant as that of the tensile scale; the nanoindentation modulus is mainly impacted by the MFA and longitudinal stiffness but also by the shear and transverse modulus (Eder et al., 2012; Jäger et al., 2011), the latter being very low for flax fibres (Bourmaud and Baley, 2009). Thus, nanoindentation does not enable a suitable and absolute longitudinal modulus to be obtained, but it is a good method for comparing efficiency and quantifying differences between a range of fibres. Our results clearly confirmed the hierarchy of properties addressed in literature with a higher cell wall stiffness for flax, highlighting the influence of MFA and parietal composition on the mechanical performance of plant fibres. At the single fibre tensile scale, another key parameter is the lumen size, which is generally large on wood (Fig. 2D), whereas it represents only a few percent of the cross section of flax fibre, which highly impacts the apparent stiffness and strength (Table 3) when the whole fibre is considered. In addition, Table 3 also shows biochemical composition of flax, VT and WF FV; additional informations can be correlated to mechanical properties and especially the cellulose content (indicated here by the glucose fraction) which is significantly higher for flax compared to VT and WF fibres; in addition, as usual for gelatinous fibres, lignin content is very low for flax fibres compared to fibres from wood species. Regarding other components and main differences between WF and VT, one can notice the important mannose content in WF $(12.08 \pm 0.73 \%$ against $1.73 \pm 0.24$ $\%$ for the VT), probably due to its important content in galactomannans, strongly found in the cell walls of softwoods. Oppositely, the xylose amount is lower for the WF, this sensitive and labile sugar being probably impacted by the extraction treatment applied to obtain WF fibres.

\subsection{Mechanical properties after the first injection}

Fig. 2 presents the average tensile stress-strain curve and Table 4 illustrates the results of the Young's modulus, strength and finite strain for the raw PP and associated composites. All data corresponds to the first injection cycle, before any recycling stages. In addition, Fig. 3 shows the evolution of fibre length distribution before and after injection, for each considered composite.

The stress-strain curves show similar general trends but the impact of the fibre origin is clearly visible. As expected, the incorporation of wood or flax fibres leads to a significant stiffening of the PP which results in a lower elongation, but a significant improvement of the Young's modulus and stress at break. Significant differences in reinforcement are found depending on their nature.

Focusing on the Young's modulus, very similar values obtained for WF, Flax and VT/Flax composite with a stiffness around $3.600 \mathrm{GPa}$ (Table 4) can be observed. Surprisingly, the post-injection aspect ratios (Table 2) and the fibre structures are very different (Fig. 1), based on these data, the performance of the PP/flax composite should be superior. However, in an injected composite material, while the fibre length and aspect ratio are important parameters, the microstructure of the parts and the interface between fibres and matrix are also significant, and can lead to unintuitive results, as has been shown for example on injected PP-Jute compounds (Tanguy et al., 2018). The composition of the cell walls is also a factor of the first order, a very significant difference in composition exists between flax and wood as demonstrated through the biochemical assessment and values given in Table 3. Flax fibres contain a very high fraction of cellulose (with pectic and hemicellulosic polymers in a lesser proportion), whereas wood fibres have reduced fraction of cellulose but more important lignin and xylose content (Bourmaud et al., 2018). It has been shown that lignin, especially when incorporated

Table 4

Quasi static tensile test result of the four studied compounds and PP after the first injection (Recycling cycle 0).

\begin{tabular}{llll}
\hline Sample & $\begin{array}{l}\text { Young Modulus } \\
(\mathrm{MPa})\end{array}$ & Strength $(\mathrm{MPa})$ & $\begin{array}{l}\text { Strain at break } \\
(\%)\end{array}$ \\
\hline PP cycle 0 & $1,576 \pm 48$ & $25.1 \pm 0.7$ & $4.3 \pm 0,3$ \\
PP-Flax cycle 0 & $3,606 \pm 316$ & $38.5 \pm 0.2$ & $3.4 \pm 0,3$ \\
PP-VT cycle 0 & $2,906 \pm 140$ & $28.7 \pm 0,1$ & $3.3 \pm 0.2$ \\
PP-WF cycle 0 & $3,629 \pm 72$ & $40.8 \pm 0,1$ & $2.6 \pm 0.1$ \\
PP-VT/Flax cycle 0 & $3,586 \pm 139$ & $37.4 \pm 0,4$ & $2.7 \pm 0.2$ \\
\hline
\end{tabular}

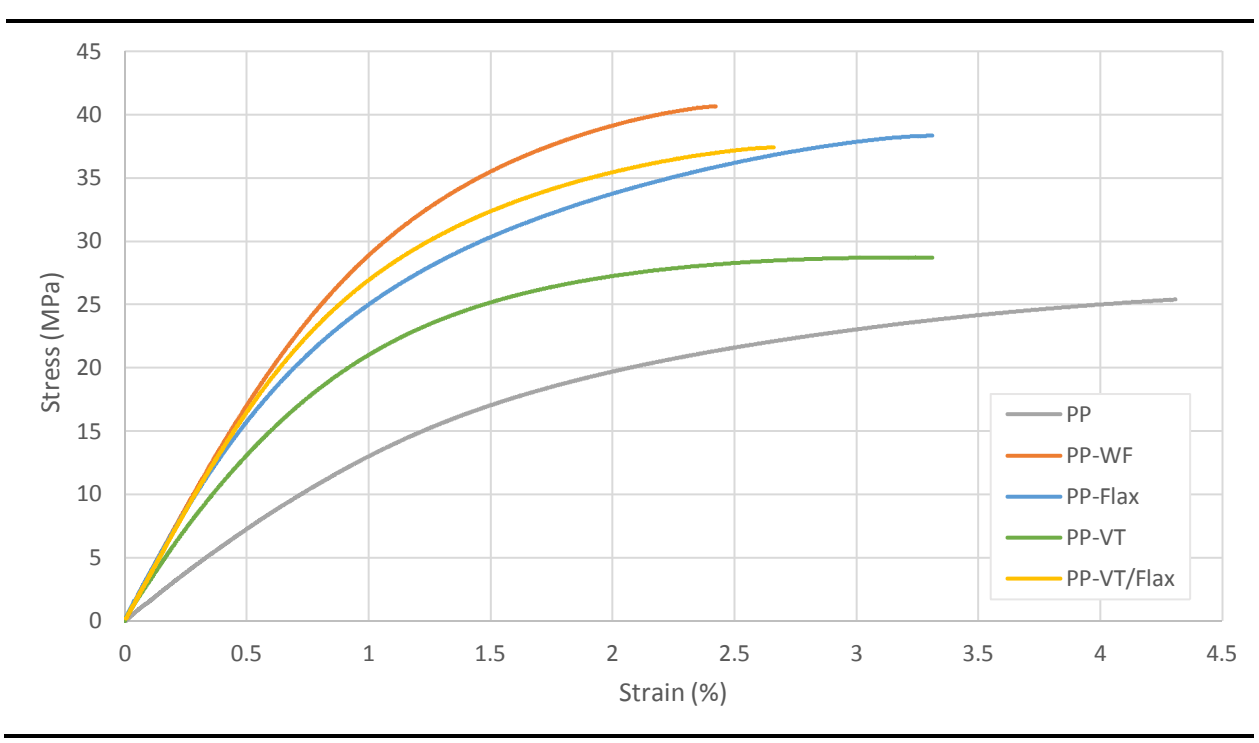

Fig. 2. Average tensile curves of the samples after the first injection (recycling cycle 0). 


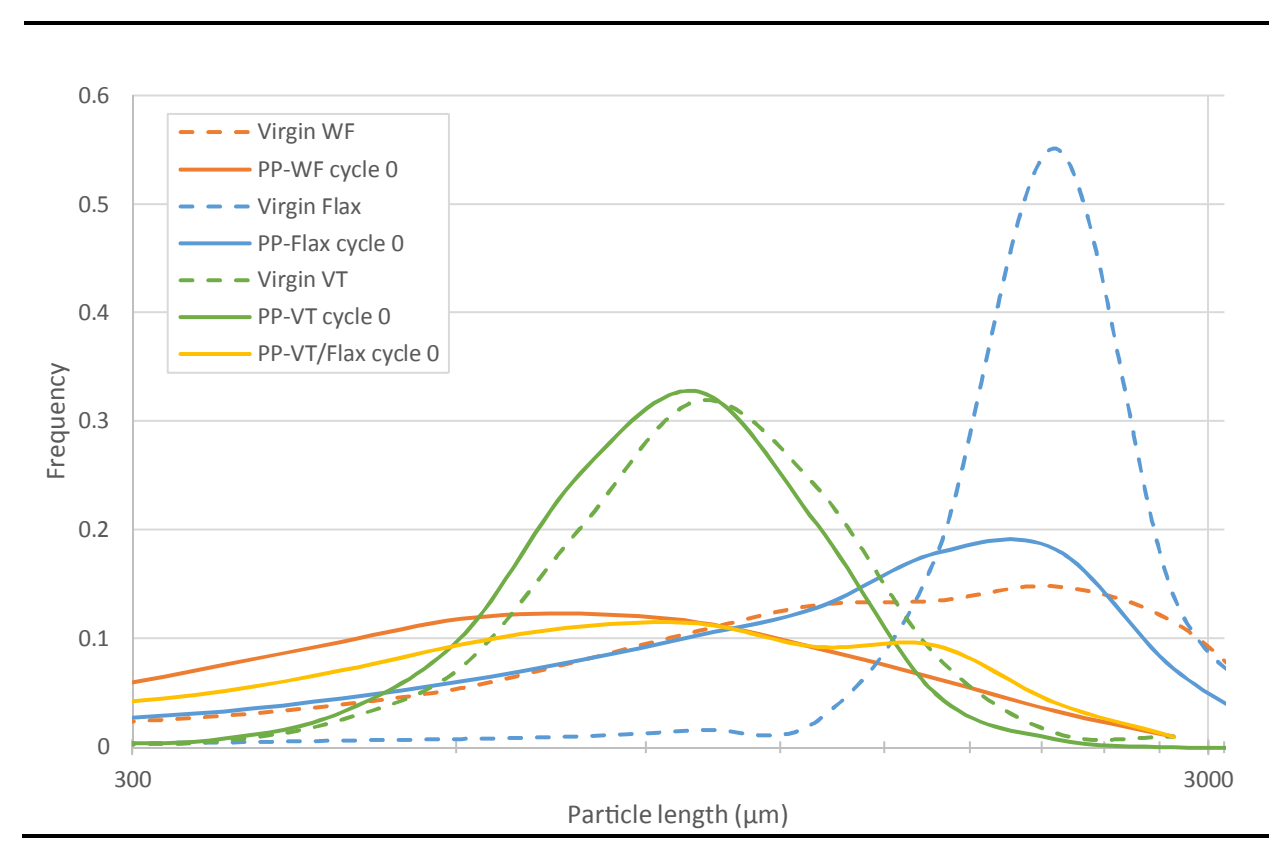

Fig. 3. Distribution of equivalent particle lengths LEFI of the reinforced fibre particles before and after injection (with logarithmic scale).

in a PP matrix, plays a role as an adhesion promoter (Graupner et al., 2014). Fig. 4 shows SEM images focusing on a fibre matrix interface for $\mathrm{PP} /$ flax and PP/WF. Interestingly, flax fibres (Fig. 4A and B) are cleaner and matrix free compared to WF fibres (Fig. 4C and D), proving the strong fibres/matrix interface adhesion of wood particles, probably due in our case to high lignin content of VT fibres. This performing interface
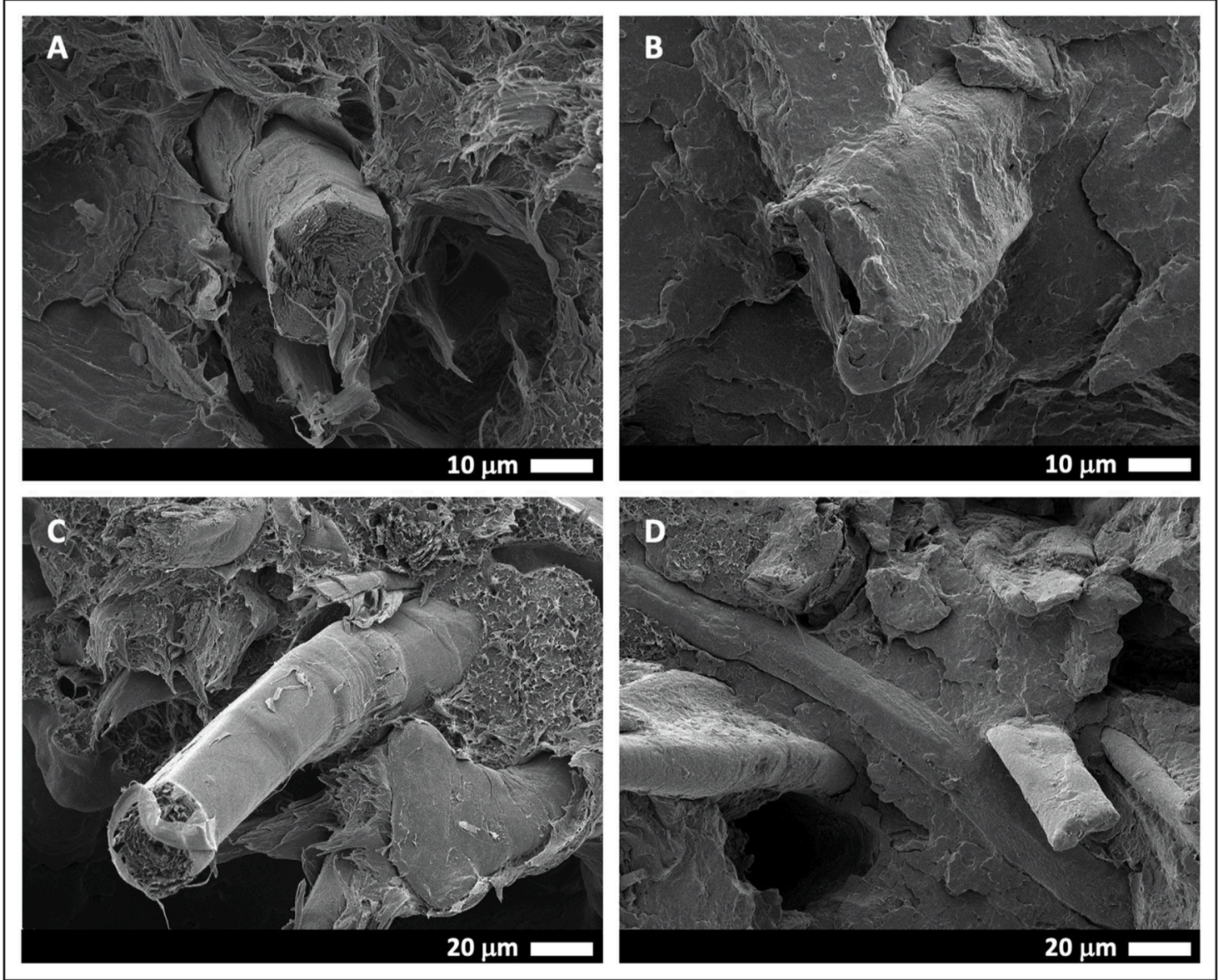

Fig. 4. SEM pictures of the fibres of the breaking pattern after the tensile test at recycling cycle 0 . The pictures A and B correspond to PP-Flax and the pictures $\mathrm{C}$ and D to PP-WF. 
is also assessed because a significant gap exists between the flax fibre and the matrix (Fig. 4A and B), contra WF fibres, which have a much closer contact with the matrix. These observations help to explain the very similar tensile Young's modulus between PP-Flax and wood reinforced composites. In addition, when VT is used, the composite material contains fibres with a very low aspect ratio in comparison to flax or WF, and has very short fibre lengths $(745.8 \pm 625.6 \mu \mathrm{m})$ compared to those found in PP-Flax $(1,350.1 \pm 787.9 \mu \mathrm{m})$ or even in PP-VT $(979.4 \pm 322.4$ $\mu \mathrm{m})$. It also exhibits a significantly different distribution (Fig. 3), due to the presence of different particles (i.e. flax fibres and wood particles); thus, two peaks (approx. 1,000 $\mu \mathrm{m}$ and 1,600 $\mu \mathrm{m}$ ) corresponding to the two populations are clearly visible in Fig. 3. It would have been logical to obtain a particle length intermediate to these two mixtures. It is therefore likely that the addition of wood particles with flax produced synergy and increased shear, probably favour better dispersion and individualization of the reinforcements.

Irrespective of the formulations studied, an increase in stiffness is observed when compared to virgin PP (Table 4), even for PP-VT which has a $+84 \%$ increase in the Young's modulus compared to the matrix. It is lower than that of the other three compounds (approx. $+130 \%$ ), mainly due to the aspect ratio of VT fibres after injection which is only 9.1, the others being between 17.5 and 37.5.

The different observations made for the modulus are also valid for the maximum strength which follows the same trend, even if the increase is lower for PP-VT. All composite materials have a higher strength than the matrix, which demonstrates their reinforcing effect, even for modest aspect ratios. In an injected composite, the stress values are mainly impacted not only by the individualisation of the reinforcements, by their aspect ratio and by their mechanical properties but also by the quality of the fibre-matrix interface, as previously discussed and supported by Fig. 4. The results presented in Table 4 show, as for the modulus, significantly higher values of strength at max for the PP-Flax, PP-VT and PP-WF compounds, which confirms the hypotheses presented previously and in particular the improved interface when the composite contains wood fibres, due to their high lignin content (Table 3).

Moreover, compatibilizing agents such as those we have used were mainly developed for plant fibre composites incorporating wood (boosted by the decking industry) and not annual plant fibres with a lower lignin content.

The strain corresponding to the maximum of the stress-strain curves is also significantly impacted by the addition of plant fibres (Table 4). In any case, it leads to a decrease in this elongation, but PP-flax retains an interesting elongation, which demonstrates the importance of the role of the length of the fibres, higher in this case (Table 2), for this parameter. This is also the case for PP-VT but for a different reason, the lower stiffness of this material naturally leads to a higher elongation. The other two composites, PP-WT and PP-VT/Flax have lower elongations due to the shorter fibre lengths in these composites.

To conclude, there are many parameters which impact the tensile test results of the studied composites. The aspect ratio, fibre length and fibre/matrix interface probably play a key-role in the behaviour of these materials. Despite the weak fibre/matrix interface, the aspect ratio and the fibre's length are the assets of the PP-Flax composite which enables it to obtain notable stiffness properties. Conversely, PP-WF has approximatively the same stiffness results due to an advantageous balance between fibre/matrix adhesion and aspect ratio. Because of its weak aspect ratio, PP-VT has lower stiffness results than flax or WF reinforced composites, and consequently a significant elongation. In all cases, the addition of vegetal particles in a PP matrix considerably increases the stiffness of the final composite and decreases the elongation.

\subsection{Modelling of the mechanical performances of the composites}

The effective properties of the composite are conducted on the compound made after the first injection (recycling cycle 0). The PP matrix undergoes an elasto-plastic ductile damage behaviour. An isotropic hardening power function is defined such as $R(p)=k p^{m}$. The hardening $(k, m)$ and the damage $\left(S_{0}, s\right)$ parameters are obtained from fitting the experimental curve of the matrix PP. Values of $\mathrm{k}, \mathrm{m}, \mathrm{S}_{\mathrm{o}}$ and $\mathrm{s}$ are $135 \mathrm{MPa}, 0.51,4 \mathrm{MPa}$ and 0.1 , respectively. The Young modulus, Poisson ratio and yield stress of the matrix are $1,576 \mathrm{MPa}, 0.36$ and $7 \mathrm{MPa}$, respectively.

The properties of the reinforcements considered for this modelling work are given in Table 5. The Young's Modulus and Poisson's ratio come from literature data and the fibre volume fraction and aspect ratio come from the experimental results of the present work (Tables 1 and 2).

Table 6 compares the composites response in terms of the Youngs's modulus, the maximum strength, and the strain at break between the experiments and the numerical modelling for the recycling cycle 0 . An overall good agreement is found between both the experimental and numerical results, confirming the pertinence of the numerical model developed here.

Fig. 5 shows the comparison of the tensile behaviour of the studied composites from experimental tests (Fig. 5A) with the numerical simulation (Fig. 5B). The two main influential parameters on the effective behaviour of the composites are the fibre aspect ratio $\mathrm{L} / \mathrm{D}$ and the volume fraction $\mathrm{f}_{\mathrm{I}}$. It is well-known that the volume fraction tends to stiffen the global response of the composite. The higher the volume fraction, the stiffer the composite through its Young's modulus, yields stress and hardening modulus. This trend is confirmed for each composite versus the matrix phase in Fig. 5. The aspect ratio is the second design parameter to account for the effective behaviour. An enhancement of the macroscopic stress-strain response with the increasing of the aspect ratio can be observed from an experimental or numeric point of view.

More detailed comments can be added for each study case considered:

Composite PP-VT: Fig. 6A depicts a good agreement between the experimental results and the numerical predictions. The effective behaviour of the composite follows a trend governed by the nonlinear matrix phase. In the elastic range, numerical predictions fit experimental results well, leading to a Young's modulus with a moderate relative error of $6.5 \%$. In the plastic domain, the softening of the composite is predicted fully with a close evolution to the experimental response.

Composite PP-Flax: Its behaviour is shown in Fig. 6B. An increase of the composite's characteristics in terms of the Young's modulus, the initial yield strength and the plastic hardening modulus can be observed. This enhancement is due to the aspect ratio of the fibres. The higher the aspect ratio, the stiffer the mechanical properties. In the elastic range, the numerical predictions perfectly fit experimental results with a Young's modulus relative error of $0.3 \%$. Note that for flax fibres, the Young's Modulus of single fibres can be experimentally measured, which is not the case for VT or WF fibres; for the latter two, values come from literature and, although the authors have selected wood species close to those used here, small differences may occur in the stiffness of

Table 5

Material properties, volume fraction and aspect ratio of flax, VT, WF and VT/ Flax for the Recycling cycle $0 . *$ indicates average value of VT and flax fibre modulus.

\begin{tabular}{|c|c|c|c|c|}
\hline Reinforcements & $\begin{array}{l}\text { Young modulus } E \\
(G P a)\end{array}$ & $\begin{array}{l}\text { Poisson's ratio } \\
\nu\end{array}$ & $\begin{array}{l}\text { Fibre } \\
\text { volume } \\
\text { fraction Vf }\end{array}$ & $\begin{array}{l}\text { Aspect } \\
\text { ratio } L / D\end{array}$ \\
\hline Flax & $\begin{array}{l}52.5 \text { - (Scida } \\
\text { et al., 2017) }\end{array}$ & $\begin{array}{l}0.498 \text { - (Scida } \\
\text { et al., 2017) }\end{array}$ & 0.204 & 37.5 \\
\hline Vegetal Technic & $\begin{array}{l}30 \text { - (Jäger et al., } \\
\text { 2011) }\end{array}$ & $\begin{array}{l}0.33 \text { - (Jäger } \\
\text { et al., 2011) }\end{array}$ & 0.21 & 9.1 \\
\hline WoodForce & $\begin{array}{l}25 \text { - (Pupure et al., } \\
2020 \text {; Sobczak } \\
\text { et al., 2012) }\end{array}$ & $\begin{array}{l}0.33 \text { - (Jäger } \\
\text { et al., 2011) }\end{array}$ & 0.21 & 17.5 \\
\hline $\begin{array}{l}\text { Vegetal Technic } \\
\text { / Flax }\end{array}$ & $41.25^{*}$ & $0.41^{*}$ & 0.207 & 18.5 \\
\hline
\end{tabular}


Table 6

Mechanical properties of the four studied compounds and PP after the first injection (Recycling cycle 0 ).

\begin{tabular}{|c|c|c|c|c|c|c|}
\hline \multirow[t]{2}{*}{ Sample } & \multicolumn{2}{|l|}{$\begin{array}{l}\text { Young Modulus } \\
\text { (MPa) }\end{array}$} & \multicolumn{2}{|l|}{$\begin{array}{l}\text { Strength } \\
(\mathrm{MPa})\end{array}$} & \multicolumn{2}{|c|}{$\begin{array}{l}\text { Strain at break } \\
(\%)\end{array}$} \\
\hline & Exp. & Num. & Exp. & Num. & Exp. & Num. \\
\hline $\begin{array}{l}\text { PP-Flax } \\
\text { cycle } 0\end{array}$ & $3,606 \pm 316$ & 3,616 & $38.5 \pm 0,2$ & 41.5 & $3.4 \pm 0,3$ & 1.8 \\
\hline $\begin{array}{l}\text { PP-VT } \\
\text { cycle } 0\end{array}$ & $2,906 \pm 140$ & 2,717 & $28.7 \pm 0,1$ & 28.91 & $3.3 \pm 0.2$ & 3.0 \\
\hline $\begin{array}{l}\text { PP-WF } \\
\text { cycle } 0\end{array}$ & $3,629 \pm 72$ & 3,346 & $40.8 \pm 0,1$ & 42.18 & $2.6 \pm 0.1$ & 2.2 \\
\hline $\begin{array}{l}\text { PP-VT/ } \\
\text { Flax } \\
\text { cycle } 0\end{array}$ & $3,586 \pm 139$ & 3,329 & $37.4 \pm 0,4$ & 37.77 & $2.7 \pm 0.2$ & 2.7 \\
\hline
\end{tabular}

the fibres used. However, at the plastic deformation stage, the numerical predictions remain stiffer than the experiment. This stiffness result is explained in the first instance by the perfect interface assumption used in the modelling which is not the case here (Fig. 4). In addition, only the ductile damage of the matrix is accounted for in the modelling, while the fibres are considered to be linear elastic. So, the damage in the fibres is not accounted for in the present modelling. As a further enhancement, an interfacial behaviour can be considered in the model by introducing discontinuities in the displacement and/or stress fields at the interface. Possible analytical formulations are based on the free sliding model FSM (Ghahremani, 1980) and interface stress model ISM (Duan et al., 2005) as well as linear spring model LSM (Qu, 1993).

Composite PP-WF: Fig. 6C shows a good agreement between the numerical predictions and the experiments at the elastic range. The Young's modulus relative error is about $7.7 \%$, probably due to a small approximation in fibre stiffness, as discussed previously. In the plastic domain, a close outcome is obtained between the numerical predictions and the experimental results until a deformation $\varepsilon \approx 0.017$. Beyond that threshold, numerical results become stiffer, and follow a trend driven by the behaviour of the fibres.

Composite PP-VT/Flax: Results from the modelling in Fig. 6D show a good agreement with respect to the experiments at the elastic stage with a Young's modulus relative error of $7.2 \%$. Nevertheless, the modelling slightly underestimates the experiments at the plastic stage.

\subsection{Behaviour of plant fibre composites during recycling: evolution of} tensile mechanical properties and impact resistance

Table 7 presents the results of the morphological analysis performed on extracted fibres of the composites at 3 recycling cycles: 0,3 and 5 (respectively, after injection processes 1, 4 and 6). Equivalent length, equivalent diameter and aspect ratio are shown. In addition, Fig. 7 presents the distribution of equivalent particle lengths of the particles for these 3 recycling cycles and always for the 4 composite materials studied.

Interestingly, the same tendency for the four composites can be observed. With the recycling process, there is a decrease in the particle's length which tends to be a minimal specific value, according to the nature of reinforcement. For fibre elements, i.e. flax and WF fibres, the final length value is $299 \pm 229 \mathrm{~mm}$ and $247 \pm 203 \mathrm{~mm}$, respectively (Table 7) whereas it is $538 \pm 262 \mathrm{~mm}$ for VT particles. Thus, fibre shape seems to be more sensitive to breakage, possibly due to their aspect ratio and their specific behaviour with the melt polymer. For flax, the presence of kink-bands is also a key point, the latter being more susceptible breakage areas as demonstrated in the literature (Le Duc et al., 2011). This reduction in size is more significant for the first process than that of the following; however, note that no strict threshold is clearly visible, the number of cycles probably being insufficient for this. This phenomenon is obtained during both the grinding and the injection steps carried out at each recycling process which cuts the fibres and homogenizes their size (Albrecht et al., 2018; Beaugrand and Berzin, 2013; Berzin et al., 2014). For all the composites, the distribution width (Fig. 7) and standard deviation (Table 7) decreases with the number of cycles, evidencing a significant homogenization of the reinforcement particles. Globally, there is also a decrease in the aspect ratio with the number of recycling stages, due to the fibre length decreasing faster than the width decreasing. This explains, in Table 7 , why the aspect ratios at cycle 5 are closer between the four composites than at the cycle 0 . Only the flax composite aspect ratio remains above 10 , which is considered to be the minimal value for maintaining a potential for reinforcement in a composite material (Kelly and Tyson, 1965). With regards to the evolution of particle diameter, it is noted that the final diameter of flax and WF particles is not much higher than the average of the single cells (Table 2) from the first cycle. The diameter of VT particles is higher, the initial cells are much more cohesive and lignin-rich (Table 3), and it is difficult, even after several cycles, to individualize them correctly. These differences in behaviour observed for VT particles are also noticeable in the case of the VT-Flax compounds; it has intermediate final particle lengths and diameters between flax and VT that perfectly reflect its composition.

Fig. 8 presents the tensile strength, Young's modulus and strain at break for the raw PP and the composite materials studied. Results from cycle 0 correspond to the Table 4 data, previously discussed in section 3.2. Generally speaking, the mechanical properties of the plant fibres reinforced composites and matrix are stable with several recycling process; this observation is consistent with the scientific literature

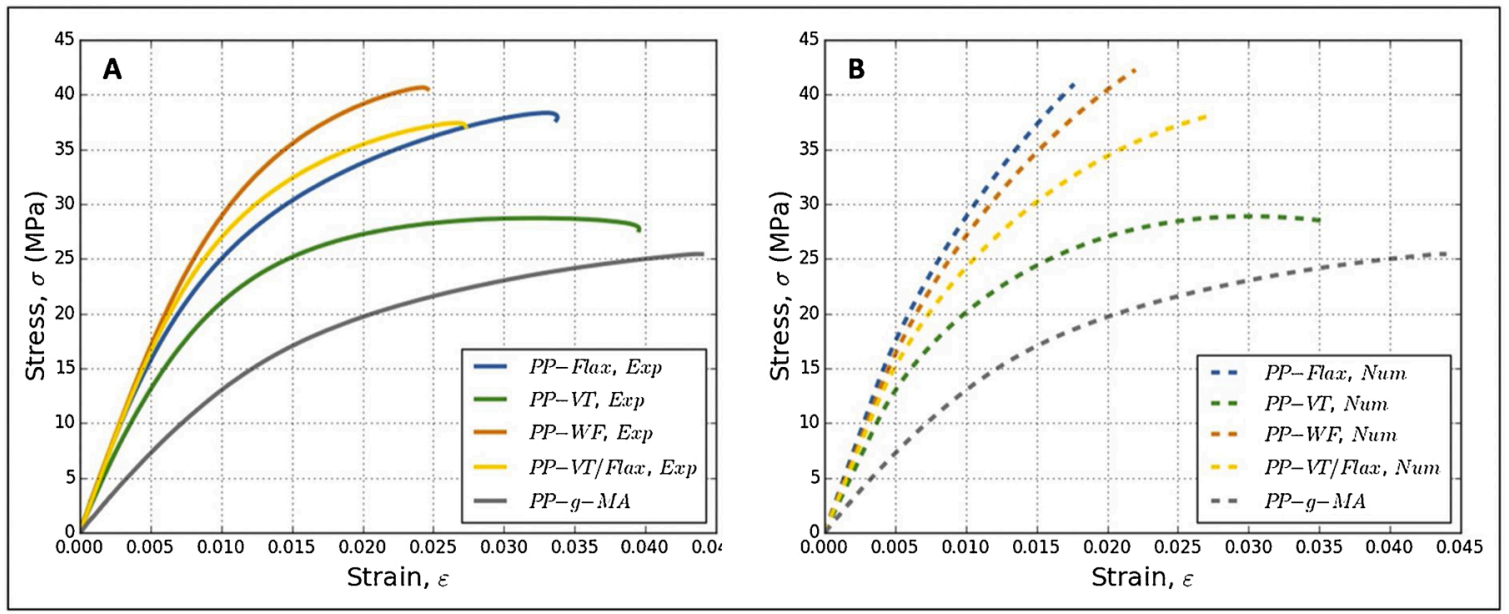

Fig. 5. Experimental (A) versus numerical (B) results of the four studied compounds and PP for the recycling cycle 0. 


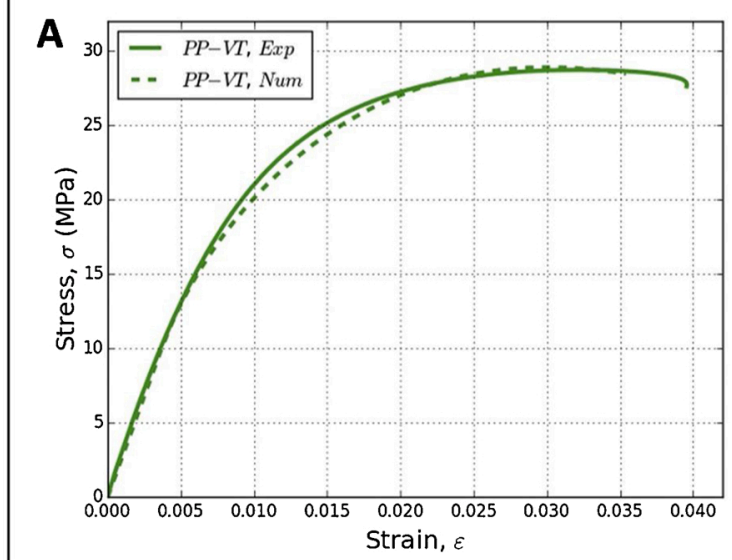

C

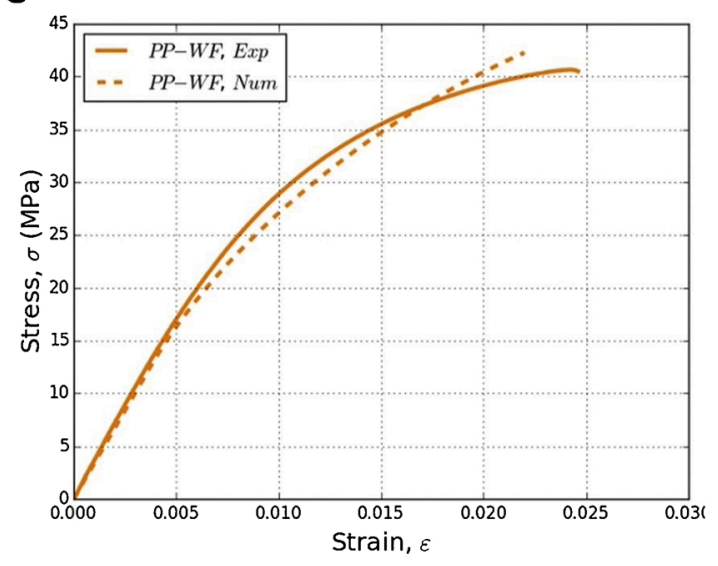

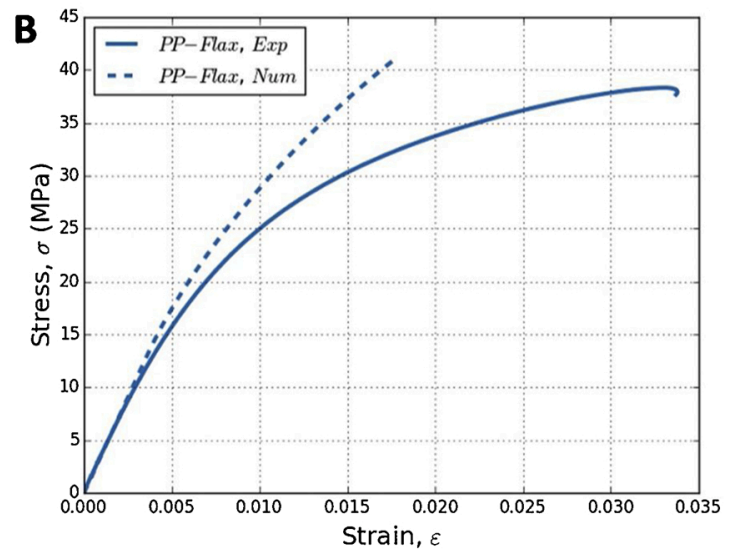

D

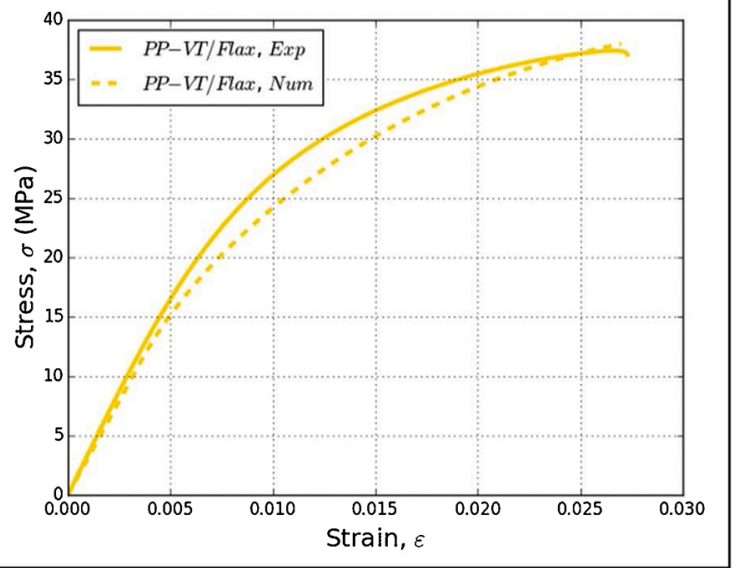

Fig. 6. Experimental versus numerical results of PP-VT (A), PP-Flax (B), PP-WF (C) and PP-VT/Flax compounds for the recycling cycle 0.

Table 7

Equivalent fibres length LEFI, equivalent fibres diameter DIFI and aspect ratio of four samples at the recycling cycles 0, 3 and 5. (PP-Flax, PP-VT, PP-WF, PP-VT/ Flax).

\begin{tabular}{llll}
\hline Sample & $\begin{array}{l}\text { Fibres length LEFI } \\
(\mu \mathrm{m})\end{array}$ & $\begin{array}{l}\text { Fibres diameter DIFI } \\
(\mu \mathrm{m})\end{array}$ & $\begin{array}{l}\text { Aspect ratio } L / \\
D\end{array}$ \\
\hline PP-Flax cycle 0 & $1,021 \pm 737$ & $27.2 \pm 14.6$ & 37.5 \\
PP-Flax cycle 3 & $439 \pm 351$ & $24.9 \pm 12.4$ & 17.6 \\
PP-Flax cycle 5 & $299 \pm 229$ & $23.6 \pm 10.3$ & 12.7 \\
PP-VT cycle 0 & $979 \pm 322$ & $107.4 \pm 38.0$ & 9.1 \\
PP-VT cycle 3 & $689 \pm 289$ & $89.4 \pm 35.1$ & 7.7 \\
PP-VT cycle 5 & $538 \pm 262$ & $77.7 \pm 33.8$ & 6.9 \\
PP-WF cycle 0 & $727 \pm 573$ & $42.0 \pm 42.1$ & 17.5 \\
PP-WF cycle 3 & $326 \pm 276$ & $36.2 \pm 23.3$ & 9.0 \\
PP-WF cycle 5 & $247 \pm 203$ & $35.4 \pm 22.2$ & 6.9 \\
PP-VT/Flax & $745 \pm 626$ & $40.4 \pm 32.6$ & 18.5 \\
$\quad$ cycle 0 & & & 10.4 \\
PP-VT/Flax & $448 \pm 356$ & $42.9 \pm 35.5$ & \\
$\quad$ cycle 3 & & & 8.7 \\
PP-VT/Flax & $378 \pm 294$ & $43.4 \pm 33.9$ & \\
$\quad$ cycle 5 & & & \\
\hline
\end{tabular}

(Bourmaud et al., 2016a; Dickson et al., 2014b; Renouard et al., 2017). However, some specificities can be underlined, according to the considered composite materials. A smooth and regular decrease in strength is observed with the number of recycling cycles for PP-Flax (-15.8 \%), PP-WF (-13.5\%) and PP-VT/Flax (-7.4\%) composite materials. Conversely, the PP-VT strength slightly increases with an improvement of $+5.6 \%$ between cycles 0 and 5 . This moderate strength can be compared with the low decrease in strength observed for the $\mathrm{PP}-\mathrm{VT} /$ Flax composite, which has a significant fraction of VT particles, compared to flax and WF reinforced composites. Thus, after 5 recycling stages, the strength of PP-VT/Flax is better than PP-Flax. These results are in line with the evolution of both the particle length and aspect ratio during recycling; VT particles morphology is poorly impacted by the recycling process compared to WF or flax fibres; moreover, the successive recycling stages generally induce a better homogenisation of particles within the composite, with a decrease of the number and size of bundles which represents privileged areas of breakage (Bourmaud et al., 2013a).

Regarding the tensile Young's modulus, the trend is globally less pronounced than that of the strength. PP-Flax, PP-WF, PP-VT/Flax and PP-VT exhibit evolution, between cycle 0 and 5 , of $-12.5 \%,-4.7 \%,-4.9$ $\%$ and $+5.4 \%$. However, the tendency between the considered compounds is the same with a better recycling behaviour for the PP-VT composite. Interestingly, the PP-Flax exhibits a constant modulus value up to cycle 2 then a significant decrease to reach a final value lower than PP-WF and PP-VT/Flax. This composite also presents a significant drop in the reinforcement aspect ratio from cycle 3 compared to the others. For injected parts, the aspect ratio plays a major role in the Young's Modulus value (Halpin and Kardos, 1976). In addition, it has been proved that, due to strong biochemical composition, flax fibres are more sensitive to successive processing stages (Bourmaud et al., 2016a) than wood fibres (Soccalingame et al., 2015), the latter being more lignified and less thermolabile.

The fibre length decrease coupled with individualization and homogenization of the flax fibres during the recycling and injection processes increases the strain at break for the flax reinforced composites (PP-Flax and PP-VT/Flax). For other composite samples, strain at break is quite stable during the recycling process.

Regarding the raw PP matrix, irrespective of the considered 

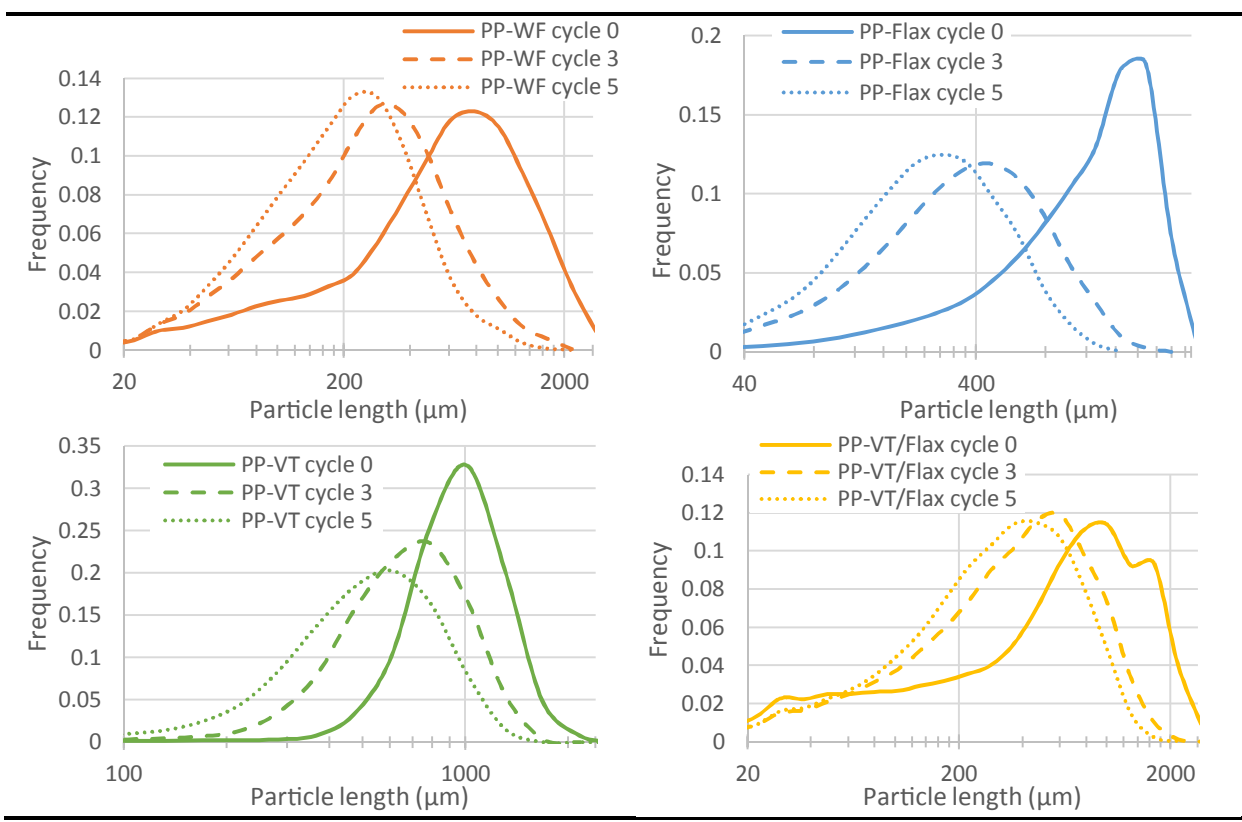

Fig. 7. Distribution of equivalent particle lengths LEFI of the reinforced fibre particles at the recycling cycles 0,3 and 5 (respectively after 1,4 and 6 injection processes) for the studied composites. PP-WF in Orange. PP-Flax in blue. PP-VT in green. PP-VT/Flax in yellow.

mechanical property, values are stable, proving as expected, the stability of this matrix (Bourmaud and Baley, 2007); it confirms the interest to consider the recycling as privileged end of life solution.

Table 8 shows the Charpy impact strength of the four studied compounds. The Charpy impact strength is stable overall for the PP-WF (-5.1 $\%)$, PP-Flax (+0.0\%) and PP-VT/Flax (+6.3\%). Interestingly, the PP-VT composite material significantly increases $(+27.7 \%)$ from cycle $0-4$. Failure and breakage behaviour are generally influenced by the deterioration of the interfacial bonding between reinforcing fibres and the matrix or the reduction of reinforcement length. When the fibres become shorter due to processing, this gives rise to a debonding processes, in favour of better impact properties. In the case of VT particles, improvement of dispersion and homogenization during recycling is also a possible advantage for impact energy properties.

These changes in mechanical performance during recycling underline the high behaviour of VT wood particles reinforced composite. Compared to long flax and WF fibres, their aspect ratio, already initially low, evolves little and their stronger adhesion with a polyolefin matrix makes them good candidates when an end of life by recycling is considered.

\subsection{Modelling after recycling - is it relevant?}

The parameter affected by the recycling cycle is mainly the aspect ratio $\mathrm{L} / \mathrm{D}$ of the reinforcements. Table 9 gives comparative values between the experimental characteristics and the numerical predictions. From Table 8, a decrease of the L/D is obtained for the selected fibres with respect to the increase of the recycling cycle, respectively cycle 3 and cycle 5 . This decrease of the aspect ratio results in a decrease of the effective mechanical performance of the composite. A similar trend is obtained for the numerical results in Table 9. With regards to recycling cycles 3 and 5, the numerical properties are decreasing, as also shown by the experimental results.

After several recycling cycles, the results of the modelling remain relevant, irrespective of the composite considered for the values of elongation and maximum stress. With regards to the Young's modulus, the model is very accurate for flax, but less so when wood particles are introduced. There is evidence that successive recycling cycles produce a strong homogenisation of the fibres in the composite (Doumbia et al.,
2015). This is probably already the case for flax at the beginning of recycling, as its fibres are already very individualised. For wood, the initial diameters are higher and recycling improves the division and therefore the homogenisation of the compound. This is confirmed by the stability of the experimental values over the recycling cycles; even if the aspect ratio decreases slightly, this decrease is compensated by the homogeneity of the blend, which is not taken into account by the model. Moreover, it has been shown by nanoindentation that the rigidity of wood fibres increases with recycling cycles under the effect of temperature, due to the cross-linking of the xylose-lignin complex (Bourmaud et al., 2020; Soccalingame et al., 2015). This may also explain the discrepancy between experimental and numerical data in the Young's modulus.

\section{Conclusion}

During this study, we compared the values obtained experimentally and numerically from injected compounds reinforced with ground wood particles. These materials were compared to the pure PP matrix and also to reference materials reinforced with wood and flax fibres.

Firstly, a fine morphological and mechanical description of the particles and fibres used allowed us to take into account the strengths and weaknesses of each of the reinforcements, and also to build a database that could be used to feed our numerical model. In particular, we were able to highlight significant differences in terms of the aspect ratio and fibre stiffness, in favour of flax fibres.

Secondly, the mechanical performances of the composites were experimentally measured and modelled. The aspect ratios of the fibres used in the models were obtained by morphological measurements after the extraction of the fibres from the injected specimens. Despite a lower performance and aspect ratio, the wood fibres and particles reached performances close to those of flax fibre reinforced composites. Their better adhesion, illustrated by electron microscopy, is the reason highlighted here. The good performance of wood fibre-reinforced composites was confirmed after the recycling stages. Flax fibre composites showed a moderate decrease in their performance after recycling, whereas wood particle composites are stable, confirming the good recycling values of wood and its ability to be used in high volumes and moderate cost applications, such as in the automotive sector. This behaviour is also 


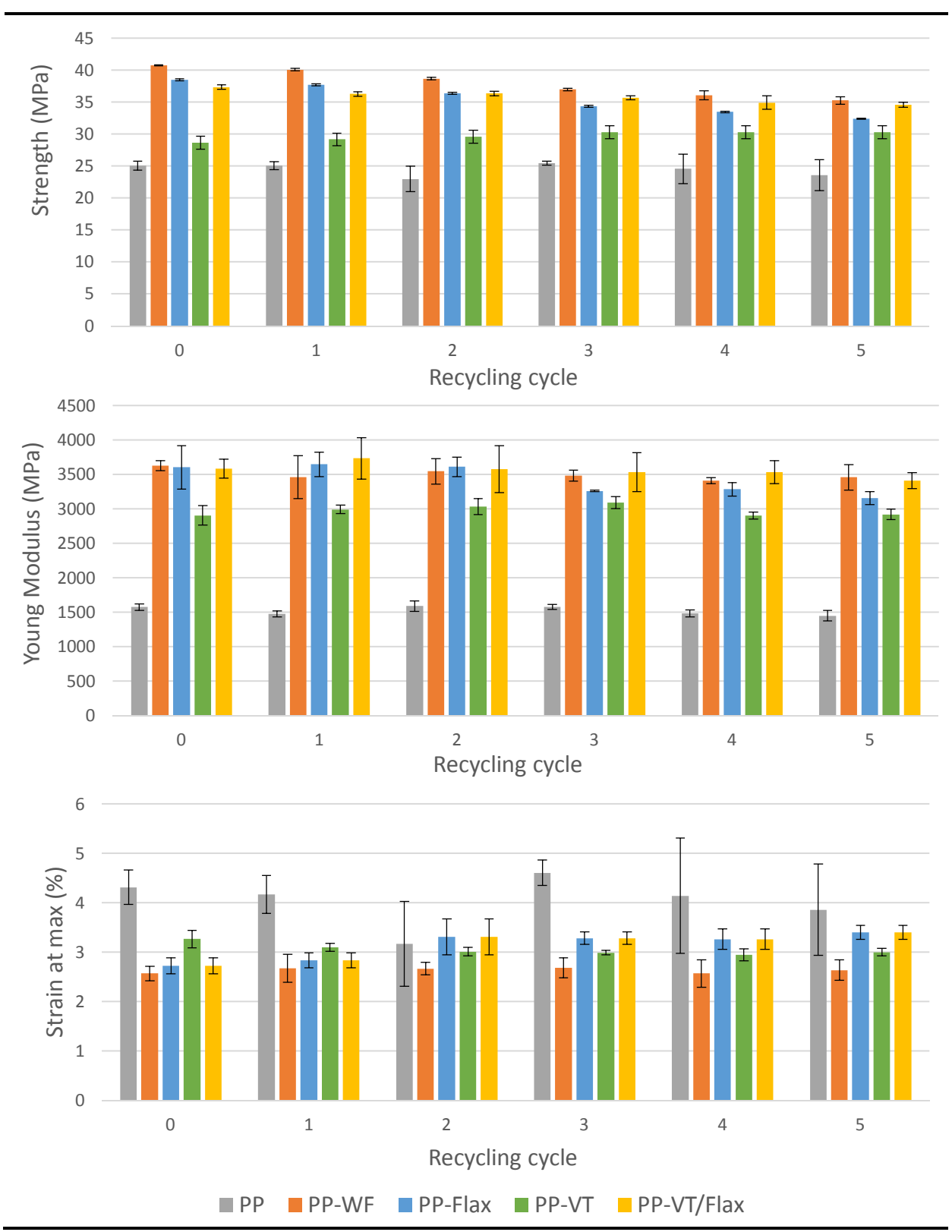

Fig. 8. Evolution of strength, Young's Modulus and strain at break during the recycling cycle of the studied composites, with reference PP.

Table 8

Charpy impact strength $\left(\mathrm{KJ} / \mathrm{m}^{2}\right)$ of the four studied compounds for each recycling cycle. Raw PP samples didn't break.

\begin{tabular}{lllll}
\hline Number of cycles & $P P$-WF & PP-VT & PP-Flax & PP-VT/Flax \\
\hline 0 & $13.7 \pm 0.5$ & $10.8 \pm 1.3$ & $17.4 \pm 0.9$ & $14.4 \pm 0.5$ \\
1 & $13.2 \pm 0.3$ & $12.2 \pm 1.1$ & $17.6 \pm 1.0$ & $14.3 \pm 0.9$ \\
2 & $13.3 \pm 0.4$ & $13.2 \pm 1.4$ & $17.8 \pm 0.9$ & $14.4 \pm 0.6$ \\
3 & $13.5 \pm 0.5$ & $13.8 \pm 1.1$ & $17.7 \pm 0.4$ & $15.9 \pm 0.9$ \\
4 & $13.1 \pm 0.8$ & $14.4 \pm 0.9$ & $18.1 \pm 0.6$ & $15.0 \pm 1.1$ \\
5 & $13.0 \pm 0.8$ & $13.8 \pm 1.2$ & $17.4 \pm 0.7$ & $15.3 \pm 1.3$ \\
Evolution Cycle 0-5 & $-5.1 \%$ & $+27.7 \%$ & $0 \%$ & $+6.3 \%$ \\
\hline
\end{tabular}

related to the good adhesion between the wood and the matrix, but also to the stability of the aspect ratio of the reinforcements, which does not decrease with recycling, unlike that of the initially longer fibres.

Subsequently, the modelling carried out demonstrated the relevance of the model used which, in general, produced results in accordance with the experimental data. The under-estimates obtained, particularly when wood is present in the composite, are linked to the fact that the improvement in the homogeneity of the mixtures was not taken into account with recycling, but also to the fact that the rigidity of the wood cell walls can evolve positively with recycling. Finally, for flax, the lower quality of the interface was not taken into account by the model. It would be interesting, in future developments, to consider these two aspects in more depth.

\section{CRediT authorship contribution statement}

Guillaume Barteau: Writing - original draft, Visualization, Investigation. Wiyao Azoti: Investigation, Conceptualization, Writing - review \& editing. Maxime Gautreau: Methodology, Investigation, Validation. Charles Francart: Methodology, Investigation, Validation. Guillaume Alès: Methodology, Investigation, Validation, Writing - review \& editing. Hamdi Jmal: Methodology, Writing - review \& editing. Jérôme Bouchet: Methodology, Investigation, Validation, Writing - review \& editing. Antoine Kervoëlen: Methodology, Investigation, Validation. 
Table 9

Static tensile test result of the four studied compounds and PP after the Recycling cycles 3 and 5 .

\begin{tabular}{|c|c|c|c|c|c|c|}
\hline \multirow[t]{2}{*}{ Sample } & \multicolumn{2}{|c|}{$\begin{array}{l}\text { Young's Modulus } \\
(\mathrm{MPa})\end{array}$} & \multicolumn{2}{|l|}{$\begin{array}{l}\text { Strength } \\
(\mathrm{MPa})\end{array}$} & \multicolumn{2}{|c|}{$\begin{array}{l}\text { Strain at break } \\
(\%)\end{array}$} \\
\hline & Exp. & Num. & Exp. & Num. & Exp. & Num. \\
\hline $\begin{array}{l}\text { PP-Flax } \\
\text { cycle } 3\end{array}$ & $3,261 \pm 12$ & 3267 & $34.4 \pm 0.2$ & 39.15 & $4.0 \pm 0.1$ & 2.8 \\
\hline $\begin{array}{l}\text { PP-VT } \\
\text { cycle } 3\end{array}$ & $3,090 \pm 87$ & 2743 & $30.3 \pm 0.2$ & 29.18 & $3.0 \pm 0.1$ & 3.0 \\
\hline $\begin{array}{l}\text { PP-WF } \\
\text { cycle } 3\end{array}$ & $3,482 \pm 80$ & 3111 & $37.0 \pm 0.2$ & 36.96 & $2.7 \pm 0.2$ & 3.0 \\
\hline $\begin{array}{l}\text { PP-VT/ } \\
\text { Flax } \\
\text { cycle } 3\end{array}$ & $3,532 \pm 283$ & 3015 & $35.7 \pm 0.2$ & 31.46 & $3.3 \pm 0.1$ & 2.7 \\
\hline $\begin{array}{l}\text { PP-Flax } \\
\text { cycle } 5\end{array}$ & $3,157 \pm 93$ & 3,066 & $32.4 \pm 0.1$ & 34.25 & $3.9 \pm 0.1$ & 3.1 \\
\hline $\begin{array}{l}\text { PP-VT } \\
\text { cycle } 5\end{array}$ & $2,923 \pm 77$ & 2,700 & $30.3 \pm 0.1$ & 28.51 & $3.0 \pm 0.1$ & 3.0 \\
\hline $\begin{array}{l}\text { PP-WF } \\
\text { cycle } 5\end{array}$ & $3,460 \pm 184$ & 2,969 & $35.3 \pm 0.6$ & 33.12 & $2.6 \pm 0.2$ & 2.8 \\
\hline $\begin{array}{l}\text { PP-VT/ } \\
\text { Flax } \\
\text { cycle } 5\end{array}$ & $3,411 \pm 118$ & 2,911 & $34.6 \pm 0.1$ & 31.75 & $3.4 \pm 0.1$ & 2.9 \\
\hline
\end{tabular}

Johnny Beaugrand: Conceptualization, Writing - review \& editing, Supervision. Nadia Bahlouli: Conceptualization, Writing - review \& editing, Supervision. Alain Bourmaud: Conceptualization, Writing review \& editing, Supervision.

\section{Declaration of Competing Interest}

The authors declare that they have no known competing financial interests or personal relationships with other people or organizations that could have appeared to influence the work reported in this paper.

\section{Acknowledgements}

The authors would like to thank the French Environment and Energy Management Agency (ADEME) for funding this work through the collaborative project COCCYBIO as well as the PSA group and Dr Ivan Roche for leading this project. We would also like to thank the INTERREG IV Cross Channel programme for funding the QICPIC equipment through the FLOWER project.

\section{References}

Albrecht, K., Osswald, T., Baur, E., Meier, T., Wartzack, S., Müssig, J., 2018. Fibre length reduction in natural fibre-reinforced polymers during compounding and injection moulding - experiments versus numerical prediction of fibre breakage. J. Compos. Sci. 2, 20-37. https://doi.org/10.3390/jcs2020020.

Azoti, W., Elmarakbi, A., 2017. Constitutive modelling of ductile damage matrix reinforced by platelets-like particles with imperfect interfaces: application to graphene polymer nanocomposite materials. Compos. Part B Eng. 113, 55-64. https://doi.org/10.1016/j.compositesb.2017.01.007.

Azoti, W.L., Koutsawa, Y., Tchalla, A., Makradi, A., Belouettar, S., 2015 Micromechanics-based multi-site modeling of elastoplastic behavior of composite materials. Int. J. Solids Struct. 59, 198-207. https://doi.org/10.1016/j. ijsolstr.2015.02.002.

Azoti, W., Jmal, H., Francart, C., Bahlouli, N., Bourmaud, A., Bouchet, J., Kervoëlen, A., Pradel, J.-L., Roche, I., 2019. Propriétés thermomécaniques et comportement élasto(visco) plastique des matériaux composites bio-sourcés. In: É.N.S. d'Arts et M. (ENSAM) (Ed.), Bordeaux, 21ème Journées Nationales Sur Les Composites. Bordeaux.

Baley, C., Bourmaud, A., 2014. Average tensile properties of French elementary flax fibers. Mater. Lett. 122, 159-161. https://doi.org/10.1016/j.matlet.2014.02.030.

Baley, C., Le Duigou, A., Bourmaud, A., Davies, P., 2012. Influence of drying on the mechanical behaviour of flax fibres and their unidirectional composites. Compos. Part A Appl. Sci. Manuf. 43 https://doi.org/10.1016/j.compositesa.2012.03.005.

Beaugrand, J., Berzin, F., 2013. Lignocellulosic fiber reinforced composites: influence of compounding conditions on defibrization and mechanical properties. J. Appl. Polym. Sci. 128, 1227-1238. https://doi.org/10.1002/app.38468.

Berzin, F., Vergnes, B., Beaugrand, J., 2014. Evolution of lignocellulosic fibre lengths along the screw profile during twin screw compounding with polycaprolactone.
Compos. Part A Appl. Sci. Manuf. 59, 30-36. https://doi.org/10.1016/j. compositesa.2013.12.008.

Blakeney, A.B., Harris, P.J., Henry, R.J., Stone, B.A., 1983. A simple and rapid preparation of alditol acetates for monosaccharide analysis. Carbohydr. Res. 113 (2), 291-299.

Bourmaud, A., Baley, C., 2007. Investigations on the recycling of hemp and sisal fibre reinforced polypropylene composites. Polym. Degrad. Stab. 92, 1034-1045. https:// doi.org/10.1016/j.polymdegradstab.2007.02.018.

Bourmaud, A., Baley, C., 2009. Rigidity analysis of polypropylene/vegetal fibre composites after recycling. Polym. Degrad. Stab. 94, 297-305. https://doi.org/ 10.1016/j.polymdegradstab.2008.12.010.

Bourmaud, A., Ausias, G., Lebrun, G., Tachon, M.-L.L., Baley, C., 2013a. Observation of the structure of a composite polypropylene/flax and damage mechanisms under stress. Ind. Crops Prod. 43, 225-236. https://doi.org/10.1016/j. indcrop.2012.07.030.

Bourmaud, Alain, Morvan, C., Bouali, A., Placet, V., Perré, P., Baley, C., 2013b. Relationships between micro-fibrillar angle, mechanical properties and biochemical composition of flax fibers. Ind. Crops Prod. 44, 343-351. https://doi.org/10.1016/j. indcrop.2012.11.031.

Bourmaud, A., Gibaud, M., Lefeuvre, A., Morvan, C., Baley, C., 2015. Influence of the morphology characters of the stem on the lodging resistance of Marylin flax. Ind. Crops Prod. 66, 27-37. https://doi.org/10.1016/j.indcrop.2014.11.047.

Bourmaud, Alain, Akesson, D., Beaugrand, J., Le Duigou, A., Skrifvars, M., Baley, C., 2016a. Recycling of L-Poly-(lactide)-Poly-(butylene-succinate)-flax biocomposite. Polym. Degrad. Stab. 77-88. Available.

Bourmaud, A., Gibaud, M., Baley, C., 2016b. Impact of the seeding rate on flax stem stability and the mechanical properties of elementary fibres. Ind. Crops Prod. 80 https://doi.org/10.1016/j.indcrop.2015.10.053.

Bourmaud, A., Beaugrand, J., Shah, D.U., Placet, V., Baley, C., 2018. Towards the design of high-performance plant fibre composites. Prog. Mater. Sci. 97, 347-408. https:// doi.org/10.1016/j.pmatsci.2018.05.005.

Bourmaud, A., Mayer-Laigle, C., Baley, C., Beaugrand, J., 2019. About the frontier between filling and reinforcement by fine flax particles in plant fibre composites. Ind. Crops Prod. 141, 111774 https://doi.org/10.1016/j.indcrop.2019.111774.

Bourmaud, A., Shah, D.U., Beaugrand, J., Dhakal, H.N., 2020. Property changes in plant fibres during the processing of bio-based composites. Ind. Crops Prod. 154, 112705 https://doi.org/10.1016/j.indcrop.2020.112705.

Burgert, I., Fruhmann, K., Keckes, J., Fratzl, P., Stanzl-Tschegg, S.E., 2002. Microtensile testing of wood fibers combined with video extensometry for efficient strain detection. Holzforshung 57, 661-664.

Burgert, I., Eder, Æ.M., Fruhmann, K., Keckes, J., Fratzl, P., Stanzl-Tschegg, S., 2005. Properties of Chemically and Mechanically Isolated Fibres of Spruce (Picea Abies wL. x Karst.). Part 3: Mechanical Characterisation. Holzforshung, p. 59.

Da Silva, J., Panzera, T., Christoforo, A., Campos Rubio, J., Scarpa, F., 2012. Micromechanical analysis of hybrid composites reinforced with unidirectional natural fibres, silica microparticles and maleic anhydride. Mater. Res. 15, 1003-1012. https://doi.org/10.1590/S1516-14392012005000134.

Dickson, A.R., Even, D., Warnes, J.M., Fernyhough, A., 2014a. The effect of reprocessing on the mechanical properties of polypropylene reinforced with wood pulp, flax or glass fibre. Compos. Part A Appl. Sci. Manuf. 61, 258-267. https://doi.org/10.1016/ j.compositesa.2014.03.010.

Dickson, A.R., Even, D., Warnes, J.M., Fernyhough, A., 2014b. The effect of reprocessing on the mechanical properties of polypropylene reinforced with wood pulp, flax or glass fibre. Compos. Part A Appl. Sci. Manuf. 61, 258-267. https://doi.org/10.1016/ j.compositesa.2014.03.010.

Doghri, I., 2000. Mechanics of Deformable Solids: Linear, Nonlinear, Analytical and Computational Aspects.

Doumbia, A.S.A.S., Castro, M., Jouannet, D., Kervoëlen, A., Falher, T., Cauret, L., Bourmaud, A., 2015. Flax/polypropylene composites for lightened structures: multiscale analysis of process and fibre parameters. Mater. Des. 87, 331-341. https://doi.org/10.1016/j.matdes.2015.07.139.

Duan, H.L., Wang, J., Huang, Z.P., Karihaloo, B.L., 2005. Size-dependent effective elastic constants of solids containing nano-inhomogeneities with interface stress. J. Mech. Phys. Solids 53, 1574-1596. https://doi.org/10.1016/j.jmps.2005.02.009.

Eder, M., Stanzl-Tschegg, S.E., Burgert, I., 2008. The fracture behaviour of single wood fibres is governed by geometrical constraints: in situ ESEM studies on three fibre types. Wood Sci. Technol. 42, 679-689.

Eder, M., Arnould, O., Dunlop, J.W.C., Hornatowska, J., Salmen, L., 2012. Experimental micromechanical characterisation of wood cell walls. Wood Sci. Technol.

Eshelby, J.D., Peierls, R.E., 1957. The determination of the elastic field of an ellipsoidal inclusion, and related problems. Proc. R. Soc. London. Ser. A Math. Phys. Sci. 241, 376-396. https://doi.org/10.1098/rspa.1957.0133.

Evert, R.F., 2006. Esau's Plant Anatomy:Meristems, Cells, and Tissues of the Plant Body: Their Structure, Function, and Development. Wiley-Interscience.

Gassan, J., Bledzki, A.K., 1999. Possibilities for improving the mechanical properties of jute/epoxy composites by alkali treatment of fibres. Compos. Sci. Technol. 59, 1303-1309. https://doi.org/10.1016/S0266-3538(98)00169-9.

Ghahremani, F., 1980. Effect of grain boundary sliding on anelasticity of polycrystals. Int. J. Solids Struct. 16, 825-845. https://doi.org/10.1016/0020-7683(80)90052-9.

Graupner, N., Fischer, H., Ziegmann, G., Müssig, J., 2014. Improvement and analysis of fibre/matrix adhesion of regenerated cellulose fibre reinforced PP-, MAPP- and PLAcomposites by the use of Eucalyptus globulus lignin. Compos. Part B Eng. 66, 117-125. https://doi.org/10.1016/j.compositesb.2014.05.002.

Groom, L., Mott, L., Shaler, S., 2002. Mechanical properties of individual southern pine fibers. Part I. Determination and variability of stress-strain curves with respect to tree height and juvenility. Wood Fiber Sci. 34, 14-27. 
Halpin, J.C., Kardos, J.L., 1976. The Halpin-Tsai equations : a review. Polym. Eng. Sci. $16,344-352$.

Hatfield, R., Fukushima, R.S., 2005. Can lignin be accurately measured? Crop Science, 45, pp. 832-839. Lignin and Forage Digestibility Symposium. 2003 CSSA, Denver.

Jäger, A., Bader, T., Hofstetter, K., Eberhardsteiner, J., 2011. The relation between indentation modulus, microfibril angle, and elastic properties of wood cell walls. Compos. Part A Appl. Sci. Manuf. 42, 677-685. https://doi.org/10.1016/j. compositesa.2011.02.007.

Kelly, A., Tyson, W.R., 1965. Tensile properties of fibre reinforced metals: Copper/ tungsten and copper/molybdenum. J. Mech. Phys. Solids 13, 329-350.

Kersavage, P.C., 1973. A System for Automatically Recording the Load-elongation Characteristics of Single Wood Fibers Under Controlled Relative Humidity Conditions.

Le Duc, A., Vergnes, B., Budtova, T., 2011. Polypropylene/natural fibres composites: analysis of fibre dimensions after compounding and observations of fibre rupture by rheo-optics. Compos. Part A Appl. Sci. Manuf. 42, 1727-1737. https://doi.org/ 10.1016/j.compositesa.2011.07.027.

Miller, R.B., 1999. Structure of Wood, the Wood Handbook: Wood as an Engineering Material. Madison.

Mori, T., Tanaka, K., 1973. Average stress in matrix and average elastic energy of materials with misfitting inclusions. Acta Metall. 21, 571-574. https://doi.org/ 10.1016/0001-6160(73)90064-3.

Oksman, K., Mathew, A.A.P., Långström, R., Nyström, B., Joseph, K., Langstrom, R., Nystrom, R., Joseph, K., 2009. The influence of fibre icrostructure on fibre breakage and mechanical properties of natural fibre reinforced polypropylene. Compos. Sci. Technol. 69, 1847-1853. https://doi.org/10.1016/j.compscitech.2009.03.020. Experimental Techniques and Design in Composite Materials (ETDCM8) with Regular Papers.

Panshin, A.J., DeZeeuw, C., 1980. Textbook of Wood Technology. McGraw-Hil, New York.

Qu, J., 1993. The effect of slightly weakened interfaces on the overall elastic properties of composite materials. Mech. Mater. 14, 269-281. https://doi.org/10.1016/01676636(93)90082-3.

Rafighi, A., Dorostkar, A., Madhoushi, M., 2014. Investigation on mechanical properties of composite made of sawdust and high density polyethylene. Int. J. Lignocellul. Prod. 1, 134-141. https://doi.org/10.22069/ijlp.2014.2070.
Renouard, N., Mérotte, J., Kervoelen, A., Behlouli, K., Baley, C., Bourmaud, A., 2017. Exploring two innovative recycling ways for poly-(propylene)-flax non wovens wastes. Polym. Degrad. Stab. 142, 89-101.

Scida, D., Bourmaud, A., Baley, C., 2017. Influence of the scattering of flax fibres properties on flax/epoxy woven ply stiffness. Mater. Des. 122 https://doi.org/ 10.1016/j.matdes.2017.02.094.

Sobczak, L., Lang, R.W., Haider, A., 2012. Polypropylene composites with natural fibers and wood - general mechanical property profiles. Compos. Sci. Technol. 72, 550-557. https://doi.org/10.1016/j.compscitech.2011.12.013.

Soccalingame, L., Bourmaud, A., Perrin, D., Bénézet, J.-C., Bergeret, A., 2015 Reprocessing of wood flour reinforced polypropylene composites: impact of particle size and coupling agent on composite and particle properties. Polym. Degrad. Stab. 113, 72-85. https://doi.org/10.1016/j.polymdegradstab.2015.01.020.

Tanguy, M., Bourmaud, A., Baley, C., 2016. Plant cell walls to reinforce composite materials: relationship between nanoindentation and tensile modulus. Mater. Lett. 167, 161-164. https://doi.org/10.1016/j.matlet.2015.12.167.

Tanguy, M., Bourmaud, A., Beaugrand, J., Gaudry, T., Baley, C., 2018. Polypropylene reinforcement with flax or jute fibre; Influence of microstructure and constituents properties on the performance of composite. Compos. Part B Eng. 139, 64-74. https://doi.org/10.1016/j.compositesb.2017.11.061.

Tchalla, A., Azoti, W.L., Koutsawa, Y., Makradi, A., Belouettar, S., Zahrouni, H., 2015. Incremental mean-fields micromechanics scheme for non-linear response of ductile damaged composite materials. Compos. Part B Eng. 69, 169-180. https://doi.org/ 10.1016/j.compositesb.2014.08.055.

The European parliament and the council of the European union, 2000. Directive 2000/ 53/EC of the European Parliament and of the Council of the 18 September 2000 on End-of Life Vehicles.

The European parliament and the council of the European union, 2009. Regulation (EC) N ${ }^{\circ} 443 / 2009$ of the European Paliament and of the Coucil of 23 April 2009.

United Nations Framework Convention on Climate Change, 2015. Paris Agreement.

Vieville, P., Bonnet, A., Lipiński, B., 2006. Modelling effective properties of composite materials using the inclusion concept. General considerations. Arch. Mech. 58, 207-239.

Zuccarello, B., Scaffaro, R., 2017. Experimental analysis and micromechanical models of high performance renewable agave reinforced biocomposites. Compos. Part B Eng. 119, 141-152. https://doi.org/10.1016/j.compositesb.2017.03.056. 